\title{
VIEJAS CONQUISTAS Y NUEVAS FRONTERAS DEL PRINCIPIO DE OFENSIVIDAD EN LA EXPERIENCIA PENALISTA ITALIANA
}

\author{
OLD ACHIEVEMENTS AND NEW FRONTIERS OF THE \\ PRINCIPLE OF “OFFENSIVITÀ” IN THE ITALIAN \\ CRIMINAL LAW
}

GABRIELE FORNASARI ${ }^{*}$

\section{Resumen}

Después de trazar una sinopsis histórica de la doctrina italiana sobre el desarrollo de la aproximación constitucional a la teoría del delito, el artículo evalúa la crisis actual del principio de ofensividad, con una mirada crítica del interés protegido o bien jurídico, y analiza paradigmas alternativos de legitimación del Derecho penal. Ante la disyuntiva de elegir éstos o revisar y colocar nuevamente en el centro el modelo constitucional de Derecho penal, el autor opta por el último, considerando que los escenarios alternativos son inadecuados. Esto aparte, la conclusión marcha en la línea de na tendencia reciente de los jueces ordinarios y constitucionales, amén de que toda la arquitectura constitucional del Derecho penal - legalidad, culpabilidad, resocialización de los presos - se basa en y la justifica únicamente el cumplimiento cabal del principio de ofensividad, en cuya virtud pueden ser castigadas legalmente sólo las conductas que infringen intereses de relevancia constitucional.

$1 \quad$ * Catedrático de Derecho penal en la Universidad de Trento (Italia). Investigador asociado del Centro de Investigaciones de Filosofía del Derecho y Derecho penal (CIFDE) de la Universidad de Valparaíso. Traducción de José Luis Guzmán Dálbora. Gabriele.Fornasari@ unitn.it 


\begin{abstract}
After a historical framework about the italian literature on the development of the constitutional approach to the theory of crime, the article evaluates the current crisis of the principle of harmfulness, based on a critical approach to the protected interest (legal good) and analyzes alternative legitimacy paradigms of criminal law. Before the choice between dropping in favor on these or reviewing and placing again at the heart the constitutional model of criminal law, the author leans toward the latter, considering the alternatives scenarios inadequate. Moreover, this conclusion is in line with some recent trends of the ordinary and constitutional judges and above all the constitutional architecture of criminal law - legality, culpability, rehabilitation of convicts - is based on and justified only by full compliance with the principle of harmfulness (offensività), whereby only those conducts that infringe constitutionally relevant interests can be lawfully punished.
\end{abstract}

\title{
Palabras clave
}

Ofensividad - Bien jurídico - Tribunal Constitucional - Principio del daño - Posmodernidad.

\section{Keywords}

Offensività (Harmfulness) - Legal good - Constitutional Court - Harm principle - Post-modernity

\section{Introducción. Una alusión al debate de las escuelas penales del ocho- cientos.}

La doctrina penal italiana del novecientos ha vivido etapas muy diferentes.

En los primeros años de ese siglo estaba todavía presente, y con mucha fuerza, la áspera confrontación decimonona entre la Escuela clásica y la Escuela positiva, con la última que había incrementado su influencia al proponerse como elemento de modernidad de bases científicas gradualmente, pero siempre más sociológicas que biológicas, a la luz del pensamiento de Enrico Ferri-.

Los aspectos esenciales de este conflicto de escuelas son muy conocidos, también fuera de las fronteras italianas, por lo cual me permito delinearlos 
de manera muy fugaz, máxime considerando que es objeto precipuo de esta breve introducción precisamente la superación del conflicto, ocurrida entre la segunda y la tercera década del siglo.

En líneas gruesas, podría afirmar que la Escuela clásica, especialmente los desarrollos debidos al pensamiento del gran penalista toscano Francesco Carrara, propugnaba un Derecho penal fundado en principios jusracionalistas, imaginando un legislador que escribe las leyes tras haber estado en la "escuela de la razón", ${ }^{2}$ y el respeto riguroso y garantista del principio de legalidad, ${ }^{3}$ construía la teoría del delito distinguiendo fuerza física y fuerza moral, con un acento mucho más fuerte en el daño objetivo causado por el hecho ilícito, en vez que los perfiles subjetivos de la responsabilidad, y postulaba un concepto netamente psicológico de culpabilidad como noción genérica que comprende dolo y culpa, sin dar relieve alguno a juicios de valor. ${ }^{4}$ Por otro lado, veía el fin de la pena exclusivamente en la retribución del mal causado. ${ }^{5}$

Siempre de manera sintética, la Escuela positiva, que tuvo como fundador al médico veronés Cesare Lombroso, desdeñaba los fundamentos filosóficos de la escuela opuesta y partía de un vuelco radical del discurso sobre la función de la pena, a la que pensaba había que atribuir una eficacia exclusivamente preventiva, incluso prescindiendo del respeto de criterios de proporcionalidad entre ilicitud y sanción. En consecuencia, asume un

$2 \quad$ Una breve cita puede ser útil para poner en evidencia este aspecto, allí donde afirma que, al hacer ciencia del Derecho penal, "se interpreta una ley eterna e infaltable como arquetipo al que deben uniformarse las opiniones de todos los sabios, y al que debe obedecer el propio legislador". CARRARA, F.: Programma del Corso di Diritto criminale. Parte generale, $3^{\mathrm{a}}$ ed. Tip. Canovetti, Lucca, 1867. p. 25.

3 Una instancia garantista que, por lo demás, también se fundaba en una exigencia marcadamente política, desde el momento que se liga con un papel de la ciencia volcado a "frenar las aberraciones de la autoridad social en la prohibición, la represión y el juicio, por modo de mantenerla en las vías de la justicia y que no degenere en tiranía". CARRARA, F.: Programma del Corso di Diritto criminale. Parte generale, $10^{\mathrm{a}}$ ed. Fratelli Cammelli, Firenze, 1907. p. 8.

$4 \quad$ Ilustra bien las características de esta concepción, siquiera con la necesaria síntesis impuesta por los moldes de un manual, MANTOVANI, F.: Diritto penale. Parte generale, $10^{\mathrm{a}}$ ed. Cedam, Milano-Padova, 2017. pp. 279 ss.

$5 \quad$ Subrayan este importante aspecto, FIORE, C. y FIORE, S.: Diritto penale. Parte generale, $5^{\text {a }}$ ed. UTET Giuridica, Torino, 2016. p. 40, quienes reconocen en esta opción tan neta, la "consecuencia de la salida de las finalidades político-criminales de la pena fuera de la teoría del Derecho penal", especificando que "toda la atención se concentra en determinar la gravedad del delito y en la correlativa teorización de un sistema, en que las sanciones sean exactamente proporcionadas a la cantidad del delito, cual contraseña de la correspondencia casi matemática de la entidad del derecho violado y la medida de la reacción penal”. 
papel preeminente el perfil subjetivo de la teoría del delito, hasta el punto de obscurecer incluso la necesidad de un hecho típico dañoso cuando quiera que haya índices evidentes de peligrosidad social del sujeto. ${ }^{6}$

Es obvio que habría mucho más que decir al respecto, ${ }^{7}$ pero aquí interesa, sobre todo, subrayar los aspectos críticos de las dos escuelas, ${ }^{8}$ que legitimaron la reacción doctrinal que desembocó en la orientación técnicojurídica, cuyo punto de partida fue la famosa prelusión de 1910, con que Arturo Rocco asumió la cátedra de Derecho penal de la Universidad de Sassari. ${ }^{9}$

\section{La crítica a nombre de la juridicidad de la ciencia penal, en el pen- samiento de Arturo Rocco.}

El duro reproche que Rocco dirigía a ambas escuelas era, en substancia, que no hacían en verdad ciencia jurídica. ${ }^{10}$

6 Todavía hoy se puede reconocer, condensado, este punto de vista en la obra fundamental del fundador de la Escuela, LOMBROSO, C.: L'uomo delinquente in rapporto all'antropologia, alla giurisprudenza e alle discipline carcerarie. Hoepli, Milano, 1876, y también en los textos más relevantes de los otros dos principales exponentes de ella, GAROFALO, R.: Criminología. Fratelli Boca, Torino, 1891, y FERRI, E.: Sociologia criminale. Fratelli Boca, Torino, 1892, este último, en particular, decididamente orientado a ver en el delito un mero factor sintomático de la antisocialidad del autor.

$7 \quad$ No pudiendo detenerme en esta sede en ulteriores profundizaciones, remito al que considero el cuadro más exhaustivo y equilibrado de la confrontación de estas dos grandes escuelas decimononas, esto es, el aporte de DELL'ANDRO, R.: Il dibattito delle scuole penalistiche. En Archivio penale, 1958, I. pp. 173 ss.

8 Por otra parte, ellas dejaron tras sí también muy positivos legados. Cito solamente, con respecto de la Escuela clásica, el fundamento marcadamente garantista dirigido a organizar el Derecho penal como dique contra los abusos de quienes detentan el poder, y respecto de la Escuela positiva, la atención, del todo inédita en aquellos tiempos, a las condiciones sociales y psicológicas del crimen.

9 Publicada ese mismo año, ROCCO, A.: "Il problema e il metodo della scienza del Diritto penale". En: Rivista di Diritto e procedura penale, pero que citamos de ROCCO, A.: Opere giuridiche, vol. III. Edizioni del Foro, Roma, 1933. pp. 263 ss.

10 Es importante señalar, como explica un gran historiador del Derecho (GROSSI, P.: Scienza giuridica italiana. Un profilo storico 1860-1950. Giuffrè Editore, Milano, 2000. p. 67), que el viraje metodológico de Rocco se inscribe en un rumbo ya iniciado hacía algún tiempo en el ámbito del Derecho público en general, particularmente la obra de Vittorio Emanuele Orlando, importante autor que, no por azar, Rocco cita en la parte inicial de su prelusión (ROCCO, Il problema e il método, ob. cit., pp. 273 ss.), dándole el mérito de haber predicado la separación de las disciplinas del Derecho público respecto de sociología, política y filosofía, siendo la única condición del progreso de esta rama de nuestro Derecho la eliminación de las "formas más abstrusas de metafísica [que] sofocan el criterio jurídico, 
Una, la Escuela clásica, planteaba todo discurso dogmático, no sobre el Derecho vigente, sino sobre un Derecho ideal fundado en bases abstractamente racionales, con lo que hacía más filosofía que Derecho.

La otra, la Escuela positiva, fundando todo en exigencias sociales de neutralización de sujetos peligrosos e inclinados al crimen, en realidad acababa por hacer más sociología que Derecho.

Si bien desde puntos de vista muy diferentes y, en todo caso, no despreciando en principio el trabajo de quien, en el análisis jurídico, se dedica al estudio de las premisas históricas, filosóficas, sociológicas, económicas y otras, la crítica de fondo, en todo caso, era común y se focalizaba esencialmente en relevar que no puede haber ciencia jurídica en este caso, ciencia jurídico-penal- que no tenga como exclusivo punto de referencia el Derecho positivo vigente. ${ }^{11}$

El papel de la ciencia jurídica, afirma Rocco, es, por tanto, afinar dogmáticamente los conceptos deducidos de las normas del Código y las otras leyes. ${ }^{12}$

llegando casi a matarlo" (cita de ORLANDO, V. E.: I criteri tecnici per la ricostruzione giuridica del Diritto pubblico. En Archivio Giuridico, vol. XVII, 1889, pág. 113).

11 Serán todavía más directos y despectivos los juicios del estudioso que asumirá el papel de divulgador de los postulados de la orientación técnico-jurídica, el que habla de la inutilidad jurídica de las indagaciones filosóficas y los daños producidos por el ocio de la fantasía filosófica (MANZINI, V.:Trattato di Diritto penale italiano, $2^{\mathrm{a}}$ ed. Fratelli Boca, Torino, 1920, vol. I. p. 10), y de otro importante secuaz del método de Rocco, el que especifica que no hay que asignar a la ciencia penal otro objeto que el estudio de la legislación del Estado, debiéndose proscribir como simple abstracción toda elaboración derivada de principios filosóficos, ideales, racionales, naturales (MASSARI, E.: Le dottrine generali del Diritto penale. Spoleto, 1928. p. 1).

12 Es célebre y muy recordada en los cursos universitarios de Derecho penal la afirmación, enunciada como manifiesto programático, de que, "siendo así [...], no hay más remedio que [...] mantenerse firmes, apegados religiosa y escrupulosamente al estudio del Derecho, no ya de un hipotético Derecho natural, racional o ideal, [sino] sólo del Derecho positivo vigente, el único que nos proporciona la experiencia y puede ser objeto de una ciencia jurídica, como es la ciencia del Derecho penal, y que, desmentidos ya los oráculos de una antropología tan cómoda como inexacta, puede y debe permanecer así". ROCCO, Il problema e il método, ob. cit., pp. 274 ss.

Por honestidad intelectual hay que reconocer que Rocco, un jurista en todo caso muy refinado, en las páginas siguientes de este importantísimo ensayo dedica pasajes significativos a la construcción dogmática que es tarea del penalista, no reduciéndola en absoluto a la sola exégesis y, es más, admitiendo un papel incluso al discurso crítico, pero siempre dentro del horizonte limitado por la necesidad de satisfacer las exigencias del sistema propias del Derecho positivo. 
Así, se puso las bases de esa orientación técnico-jurídica que se afirmará sin discusión en los decenios sucesivos, la que, si al principio se justificó como reacción a la situación de parálisis en que se había enarenado la doctrina penal italiana a causa del insanable contraste e indisponibilidad para el diálogo de las dos escuelas principales, ambas inclinadas a ignorar el trabajo dogmático sobre el Derecho formado por el legislador, y si luego tendrá indudablemente sus méritos con la construcción de una dogmática muy refinada por parte de algunos de sus representantes, será responsable, empero, de haber cedido ante la involución autoritaria del fascismo $\mathrm{y},{ }^{13}$ acaso más, del desinterés de nuestra doctrina, que se prolongaría por decenios, por los temas de la política criminal y, en general, la cuestión de la legitimación del Derecho penal.

\section{Las consecuencias de la afirmación de la orientación técnico-jurídica.}

La más grave fue el retraso con que en mi país el Derecho penal - y lo mismo vale, incluso más, para el procedimiento penal- se ha adecuado a las pulsiones liberal-democráticas con que se reaccionó en los países europeos al término de los fascismos, y que dieron lugar, por ejemplo, en Italia y Alemania, a cartas constitucionales abiertas a una concepción moderna y garantista del Derecho y el proceso penales. ${ }^{14}$

La visión que había cristalizado en la época del liberalismo tardío con el impulso doctrinal de Rocco y los estudiosos que adhirieron a su orientación y, después, durante el fascismo, a través de un Código penal iliberal que era

13 Es muy evidente que el Código penal italiano, dictado en 1930, en plena época fascista (y vigente todavía, con muchas modificaciones), está ampliamente influido en su inspiración de fondo por la concepción en apariencia neutral en lo político (pero, en realidad, transida de vocación autoritaria) de la orientación técnico-jurídica, que nace en época liberal, pero se muestra después perfectamente funcional a los intereses del poder dictatorial, como resulta también del hecho que Arturo Rocco fue presidente de la Comisión que lo elaboró, de la que formaron parte los ya citados profesores Manzini y Massari.

14 Implícito y, no obstante, evidente es que con estas premisas lógicas y argumentales casi no queda espacio reservado a los estudios de Derecho comparado, ya que el centro de la atención de la doctrina quedaba fijado no sólo en el Derecho vigente, sino en el Derecho italiano vigente, con lo cual la exégesis y profundización cognoscitiva de los Derechos extranjeros eran consideradas completamente irrelevantes. Cfr. FORNASARI, G.: "Conquiste e sfide della comparazione penalistica". En: Dolcini, E. y Paliero, C.E.: Studi in onore di Giorgio Marinucci, vol. I, Teoria del Diritto penale, Criminologia e Politica criminale. Giuffré. Milano, 2006. pp. 265 ss. 
fiel reflejo del poder dictatorial, ${ }^{15}$ la visión, decíamos, de un jurista atento nada más que al trabajo de analizar detalladísimamente la norma vigente, tuvo como efecto la formación de una clase de penalistas que, con algunas excepciones, por hábito, pereza o comodidad no mostraban vocación alguna por la modernización y democratización de su disciplina.

Quedaba así en evidencia una paradoja que involucraba tanto a los juristas académicos como al cuerpo judicial, esto es, una inversión metodológica según la cual no es que había que interpretar el Código penal fascista según los principios vinculantes de la Constitución democrática principio de legalidad de penas y medidas de seguridad, artículo 25 , incisos segundo y tercero; principio de culpabilidad, art. 21, inc. 1; principio de la función reeducativa de la pena, art. 27, inc. 3; principio de inviolabilidad del derecho de defensa, art. 24, inc. 2; principio del juez natural preestablecido por la ley, art. 25, inc. 1; presunción de inocencia hasta la sentencia definitiva de condena, art. 27, inc. 2 ; indirectamente, principio de igualdad, art. 3-, sino que, al contrario, se creía que tales principios fuesen meramente programáticos y, por consiguiente, operantes sólo en la medida en que resultasen compatibles con los preceptos del Código. ${ }^{16}$

15 En realidad, una parte de la doctrina, en la inmediata posguerra, se empeñó en sostener la tesis de que el Código de Rocco había mantenido con vida los principios liberales de la época pre-fascista, como lo demostraría la circunstancia que sus primeros dos artículos establecieran el principio de legalidad (mientras que en la experiencia alemana de la época el principio de legalidad fue proscrito del Código), de suerte que no sería correcto definirlo un Código autoritario (así, DELOGU, T.: L'elemento politico nel Codice penale. En Archivio penale, 1945, págs. 168 y ss., y LEONE, G.: La scienza giuridico-penale nell'ultimo ventennio. En Archivio penale, 1945, págs. 23 y ss.). Sin embargo, es fácil replicar que ese era un garantismo de fachada, como quiera que una ley ordinaria (o un decreto ley) podía derogarlo, y porque durante el fascismo se presentó un amplio Derecho penal político extra codicem substraído a las garantías liberales (una crítica, ya en BRICOLA, F.: "Legalità e crisi: l'art. 25, commi 2 e 3 della Costituzione rivisitato alla fine degli anni '70". En: Questione Criminale. 1980. pp. 179 ss.)

16 Es testimonio de ello el hecho de que la Corte constitucional, instituida por la Constitución de 1948, pero que entró efectivamente en funcionamiento el año 1956, en los primeros decenios de su actividad rechazó sistemáticamente todas las objeciones de legitimidad de normas penales, habiendo modificado su jurisprudencia sólo en los años ochenta. Más adelante, veremos que ha tenido un papel importante en los años recientes, en la afirmación de la centralidad de los principios penales de la Constitución. 
En este contexto, los intentos de algunos grandes estudiosos como Antolisei, ${ }^{17}$ Bettiol ${ }^{18}$ y Nuvolone ${ }^{19}$ de reactivar reflexiones sobre los últimos fundamentos del Derecho penal, en una palabra, sobre su matriz política, restaron aislados por muchos años.

\section{Razones de la reacción contra el dominio de la orientación técni- co-jurídica.}

Como a menudo sucede en las vicisitudes del desarrollo del Derecho y su ciencia - así, por otra parte, había sucedido también con la postura de Arturo Rocco, que no fue una actitud aislada, sino que reflejó un difuso

17 Este autor se había expresado críticamente en contra de la dogmática formalista en los años del fascismo, incluyendo en el horizonte del penalista también objetivos y finalidades sociales deducibles de las normas, por lo demás dentro de un discurso caracterizado en su conjunto por una vena irracionalista (cfr. ANTOLISEI, F.: "Per un indirizzo realistico nella scienza del Diritto penale". En: Rivista italiana di Diritto penale, 1937. p. 121 ss.).

18 De este autorizado estudioso, que en la posguerra sufrió notoriamente el influjo de la doctrina existencialista, se puede recordar al respecto un amplio estudio de alcance general, en que delineó su punto de vista sobre los nexos que unen el Derecho penal a otros sectores de la experiencia y del saber (BETTIOL, G.: Il problema penale. $2^{\mathrm{a}}$ ed. Priulla, Palermo, 1948, luego incluido en Scritti giuridici, tomo II. CEDAM, Padova, 1966. p. 620 ss.), y uno más breve y específico, pero muy significativo, en que, en conclusión, hallamos afirmaciones paradigmáticas de la actitud de Bettiol, muy próximo a la Jurisprudencia de los valores, como la de que "hay que considerar superada la instancia positivista [...], cuando pretende agotar la substancia del Derecho penal en el examen de sus formas y olvidar así la matriz ética y política de que el Derecho penal surge y se alimenta", y la de que "el Derecho penal debe ser depurado de toda toxina que pueda envenenar su pureza moral, y hay que considerarlo en lo que es: ciencia de valores al servicio de la libertad humana, elaborada con un método que sepa captar concretamente estos valores, sin desecarlos en las formas geométricas del conceptualismo jurídico vacío y sin violentarlos para reducirlos al denominador de los brutales intereses en el juego utilitario" (ambas citas en BETTIOL,G.: "Orientamenti generali del Diritto penale". En: Jus, 1951, luego en Scritti giuridici, ob. cit., p. 762).

19 Cfr. NUVOLONE, P.: Natura e storia della scienza del Diritto penale. 1951, en ídem, Trent'anni di Diritto e procedura penale, vol. I. CEDAM, Padova, 1969. pp. 190 ss., quien manifiesta una profunda insatisfacción por los confines demasiado restringidos dentro de los que el jurista es llamado a desarrollar su actividad, reivindicando, en cambio, una ciencia penal que contribuya con nueva fuerza a construir el sistema de las normas a través de la naturaleza de los hechos y la lógica del pensamiento. La dogmática, sostiene Nuvolone, es una actividad insubstituible, pero es a la ciencia lo que la paráfrasis a la poesía, y el dilema de forma y substancia debe resolverse en el plano de una ciencia que aspire, con espíritu histórico, a hallar las leyes que gobiernan el contenido y las formas de las normas penales. De ahí, concluye, la necesidad de retomar los lazos con las disciplinas que estudian al hombre desde el punto de vista natural y social, para alcanzar de nuevo una ciencia penal que sea parte activa también en la construcción de normas futuras y se comprometa a fondo en la asunción de un papel crítico. 
malestar causado por el estéril debate entre las dos escuelas-, el factor desencadenante de la reacción contra el dominio de la orientación técnicojurídica tiene una dimensión esencialmente exógena.

A partir de un momento histórico que se sitúa aproximadamente entre finales de los años sesenta y principios de los setenta, empieza a cambiar la composición "sociológica" de la clase de los juristas, tanto académicos como profesionales.

Entre los abogados y magistrados que manejan las causas penales en los tribunales es cada vez más alto el número quienes no se graduaron durante los veinte años del fascismo, y lo mismo vale para los profesores que enseñan la materia en las Facultades de Derecho. Además, la Universidad de elite se ha transformado en Universidad de masa, cuyo acceso ya no está impedido a los hijos de las clases menos privilegiadas.

En este contexto, la nueva doctrina penal muestra una sensibilidad muy diferente y más acentuada por el valor de los principios constitucionales, sea en general, sea en el sector específico que es objeto de su estudio.

Esto condujo inevitablemente al inicio del abandono de un esquema de estudios penales concentrado fundamentalmente en la exégesis de las normas ordinarias, así como a la recuperación de una ciencia integrada del Derecho - y del proceso- penal, la que no puede prescindir de una conexión fuerte entre Dogmática penal y Política criminal y, en general, entre Derecho penal y ciencias sociales.

\section{El método del "Derecho penal constitucional" en la enseñanza de Franco Bricola.}

Los resultados de esta tendencia no se hicieron esperar tampoco en el plano de la producción científica.

El epicentro de la evolución de la doctrina italiana en tal sentido hay que identificarlo ciertamente en los escritos juveniles del maestro boloñés Franco Bricola y la intensa experiencia que representó, poco después, la revista "La Questione criminale", editada por la prestigiosa casa editorial "Il Mulino", también de Bolonia.

Después de sus primeros e importantes trabajos científicos de corte dogmático, que se referían al dolo y a la imputabilidad, ya en el libro dedicado a la discrecionalidad del juez penal Franco Bricola se empeña en una investigación orientada a elaborar científicamente la influencia directa de los principios de la Constitución en algunos nudos fundamentales del 
Derecho penal. ${ }^{20}$ Sin embargo, esta reflexión alcanza plena madurez con la amplísima voz sobre la teoría general del delito, publicada en 1971 en el Novissimo Digesto Italiano. ${ }^{21}$

Ya se lo apruebe o critique, este trabajo representa la piedra angular que marca el viraje de la doctrina italiana en el novecientos, hasta el punto que se puede decir que después ya nada fue igual que antes.

Desde entonces el penalista italiano se liberó de los vínculos, retazos de la orientación técnico-jurídica, que lo inhibían de ejercer un papel crítico. Entendámonos, Bricola no recorre en absoluto el camino de un abandono neo-iusnaturalista de la enseñanza conforme a la cual el Derecho vigente está en el centro de la atención del intérprete; sin embargo, reivindica para la doctrina también una función de estímulo en las decisiones políticocriminales, vinculándola en primer lugar a la afirmación de los principios innovadores de la Constitución democrática.

Por lo demás, es decisiva la mirada que se dirige a la Constitución, la que no debe ser contemplada como un conjunto de ideales programáticos, sino como una norma del ordenamiento para todos los efectos dotada de jerarquía primaria y que incide de manera directa, por una razón ineludible de deber ser, en las decisiones del legislador, la Dogmática criminal y la interpretación de la jurisprudencia. ${ }^{22}$

En la estela de Bricola, muchos estudiosos de su generación y otros más jóvenes emprenden en varios sectores del Derecho penal un intenso trabajo de revisión crítica de temas centrales, por ejemplo, la legitimación del

20 Cfr. BRICOLA, F.: La discrezionalità nel Diritto penale, vol. I, Nozione aspetti costituzionali. Giuffré, Milano, 1965. pp. 229 ss.

21 BRICOLA, F.: Teoria generale del reato, en Novissimo Digesto italiano, vol. XIV. UTET, Torino, 1973. pp. 7-93, ahora en BRICOLA, F.: Scritti di Diritto penale, vol. I. Dottrine generali, teoria del reato e sistemi sanzionatori, tomo I. Dal 1960 al 1973. Milano, 1997. pp. 539 ss. De esta obra se dispone hoy de una excelente traducción castellana, realizada por la colega colombiana Diana Restrepo Rodríguez, con la colaboración de Olmo Artale y un amplio prólogo de Massimo Donini, F. Bricola. Teoría general del delito, Montevideo-Buenos Aires, 2012.

22 Toda la voz de la Enciclopedia que hemos citado está penetrada por este espíritu, pero es digno de especial atención el parágrafo en que se enuncia una serie de consecuencias prácticas sobre la legitimidad o la interpretación de las normas vigentes a la luz del postulado de que delito puede ser sólo un hecho necesariamente ofensivo de bienes de relevancia constitucional, con referencia, por ejemplo, a los de delito presunto y de dolo específico, en la Parte general, y los de opinión, en la especial. Cfr. BRICOLA, Teoria generale del reato, ob. cit., p. 782 ss. 
Derecho penal, el sistema de sanciones y las decisiones de incriminación en la Parte especial.

Desde el punto de vista del método, como quedará de manifiesto en la "Questione Criminale", el punto clave fue ciertamente la idea de una gesamte Strafrechtswissenschaft, una ciencia integrada del Derecho penal, apoyándose en la interacción del saber jurídico con el conocimiento de las ciencias sociales, comenzando por la Criminología. ${ }^{23}$

De esta manera, se rasgaba el velo que cubre la realidad del Derecho penal material y procesal, ${ }^{24}$ ya no más objeto de un estudio meramente técnico, sino que revelado en toda su naturaleza eminentemente política.

\section{EI nuevo rostro del principio de legalidad.}

El legado de aquella época es fundamental.

En medio de muchas ingenuidades, excesos polémicos y acentos que, en el fondo, eran hijos de ese tiempo, conservamos, empero, un patrimonio de logros científicos que todavía nos condiciona, pero que en los últimos años es sometido a ataques frontales realizados en nombre de una posmodernidad líquida y tendencialmente iliberal, ${ }^{25}$ de los que es, no sólo oportuno, sino absolutamente necesario defenderlo.

Y aquí entramos en el corazón de este aporte nuestro, que se concentra en las vicisitudes del principio de ofensividad.

Sin embargo, antes hay que ocuparse de encuadrar este principio en el contexto de referencia en que lo coloca la construcción del "Derecho penal constitucional", que se remonta a la enseñanza de Bricola y los estudiosos inspirados en éste.

23 Estas características de la Revista son consecuencia directa del hecho que la codirigieran Franco Bricola y Alessandro Baratta.

$24 \quad$ No podemos tratar aquí las proyecciones en el Derecho procesal, pero vale la pena recordar que la aproximación orientada hacia la Constitución, que abre el horizonte a un discurso científico en que los valores se ponen al lado de la técnica, está muy bien ejemplificada en la espléndida y todavía muy actual monografía de NOBILI, M.: Il principio del libero convincimento del giudice. Giuffré, Milano, 1974.

25 Si bien la elaboración doctrinal de este tema es relativamente reciente, hay que registrar que anticipó sus peligros el ensayo, publicado hace veinte años, de MOCCIA, S.: "Dalla tutela di beni alla tutela di funzioni: tra illusioni postmoderne e riflussi illiberali". En: Rivista italiana di Diritto e procedura penale, 1995. pp. 343 ss. 
Ante todo, en el centro de esta arquitectura conceptual estaban los principios expresamente codificados por la Constitución republicana de 1948, que es oportuno resumir por separado en esta sede.

El principio de legalidad de penas y medidas de seguridad, establecido en los incisos segundo y tercero del artículo 25 , por cierto que no era ajeno a la experiencia penal italiana; sin embargo, como lo preveía solamente el Código penal, tenía el simple valor de un principio ordinario, por tanto, era susceptible de derogación por otra ley, cosa que sucedió con frecuencia en los años del fascismo mediante un amplio empleo del Derecho de policía, con el objeto, por ejemplo, de reprimir la disidencia política soslayando los vínculos garantistas del tipo penal a través de la referencia principal a la peligrosidad del autor.

Destacar el inderogable valor preceptivo del principio de legalidad apuntaba a hacer justicia a una situación espiritual que, todavía dos o tres decenios después de la restauración del Estado democrático, se hallaba frente a un sistema de fuentes bastante confuso, a menudo con reenvíos de leyes penales a normas de jerarquía inferior, amén de la pacífica asunción del carácter retroactivo de cambios contra reum en la jurisprudencia ${ }^{26} \mathrm{O}$ de cualquiera norma penal que no fuese estrictamente incriminadora, justificando así, por ejemplo, la aplicación retroactiva contra libertatem de un instituto ambiguo como la prescripción.

Con todo, en materia de legalidad el mérito más innovador de aquella corriente doctrinal fue haber identificado como esenciales corolarios, pese a no estar expresamente previstos en el texto constitucional, el principio de taxatividad y el objeto central de este aporte, el principio de ofensividad, sobre el que volveré detalladamente dentro de poco.

26 Este postulado era prácticamente indiscutido hasta poco tiempo atrás. Hoy, la jurisprudencia de la Corte Europea de Derechos Humanos impone superarlo al declarar la ilegitimidad de una condena basada en una nueva interpretación judicial in malam partem de una norma no modificada al tiempo del hecho (así, últimamente, CEDU, Sección IV, 14 de abril de 2015, n. 66655/13, Contrada contra Italia, publicada en Diritto penale e processo, 2015, págs. 1012 ss., de lo que se puede ver los comentarios de DONINI, M.: "Il caso Contrada e la Corte Edu. La responsabilità dello Stato per carenza di tassatività/tipicità di una legge penale retroattiva". En: Rivista italiana di Diritto e procedura penale, 2016. pp. 346 ss., y FORNASARI, G.: "Un altro passo verso la «riscrittura» della legalità? Appunti sulla sentenza Contrada”, En: AA.VV., Politica criminale e cultura giuspenalistica. Scritti in onore di Sergio Moccia. Napoli, 2017. pp. 447 ss.), pero en nuestra doctrina fue portador de esta instancia, aunque sólo en los años noventa, CADOPPI, A.: "Il principio di irretroattività". En: Insolera, G., Mazzacuva, N., Pavarini. M. y Zanotti, M.: Introduzione al sistema penale, vol. I. Torino, 1997. pp. 185 ss. 


\section{El cuadro conjunto de la visión constitucional del Derecho penal.}

Para completar la definición del cuadro, vayan ahora unas brevísimas referencias con que poner en evidencia la gran e innovadora importancia atribuida al principio de culpabilidad y al principio del carácter reeducador de la pena.

Ante todo, la doctrina del "Derecho penal constitucional" hizo valer con fuerza el argumento según el cual la personalidad de la responsabilidad penal torna inadmisibles las hipótesis de responsabilidad objetiva - nunca eliminadas del Código- $\mathrm{y}$, además, propende a una concepción normativa de la culpabilidad, por demás incompatible con la absoluta irrelevancia eximente del error o la ignorancia del precepto.

Por último, el discurso sobre la pena asumió un fuerte valor político a través del reclamo de una radical reforma penitenciaria en el sentido de la humanización y de ofrecer chances reeducativas al condenado, y la no menos importante exigencia de enriquecer el panorama de las sanciones penales con la introducción de penas alternativas a la cárcel.

Tras este cuadro de conjunto detengo el film de mi reconstrucción histórica, que pretendía representar el trasfondo de la indagación específica que quiero proponer.

En el fondo, hasta este punto se ha hablado de una evolución hacia conquistas que no eran ciertamente extrañas a la cultura jurídica de la época en el plano internacional.

En efecto, rebobinando por un momento nuestra película, un fuerte movimiento en favor de la humanización de las penas estaba operando en muchos países, a lo menos en el mundo occidental. Asimismo, el principio de culpabilidad, con sus grandes implicaciones dogmáticas y políticas, no era un descubrimiento de los cultivadores italianos del "Derecho penal constitucional", puesto que, a lo menos en los países de lengua alemana, la doctrina y, sobre todo, los tribunales hacía tiempo que razonaban en términos de una neta condena de la responsabilidad objetiva y una atribución personal y reprochable del hecho - la primera, con la afirmación de la concepción normativa de la culpabilidad en la República de Weimar, ${ }^{27}$ los segundos, desde una fundamental sentencia del Tribunal Supremo Federal de Alemania en 1952-. ${ }^{28}$

27 Un punto de referencia fue el ensayo de GOLDSCHMIDT, J.: Normativer Schuldbegriff, en Festgabe für Frank, I, Tübingen, 1930. pp. 428 ss.

$28 \quad$ BGH 2, 194. 
Un poco más complejo es el discurso relativo al amplio tema de la legalidad.

Aquí entra en juego el fundamento mismo de legitimación del Derecho penal en una sociedad democrática, como Italia procuraba fatigosamente serlo después de dos decenios de dictadura y un período, todavía en curso entonces, de soberanía limitada por obra de un potente aliado de ultramar.

Pasada la derrota bélica, en los años setenta del siglo XX la situación económica de Italia mejoró mucho, florecen extraordinarios brotes culturales en todos los campos, emergen nuevas clases sociales y se vive una fase de gran participación política. Sin embargo, por el otro lado de la medalla, todas estas conquistas, obtenidas o por alcanzar, estaban en serio peligro (lo que se sospechaba entonces, pero se descubrirá dramáticamente en el decenio sucesivo mediante las desconcertantes investigaciones de una magistratura valiente) a causa de la existencia y actividad de grupos de poder, sobre todo representados por servidores infieles al Estado, que, contemplando con admiración a las dictaduras sudamericanas, entre otros, pretendían restaurar un régimen de estampa autoritaria en obsequio a las exigencias de la Guerra fría.

Este neto contraste que caracteriza nuestra vida pública de cuarenta o cincuenta años atrás es un argumento clave para explicar cómo la afirmación del principio de legalidad poseía un valor determinante en la lucha por el mantenimiento del equilibrio democrático.

Cuando se decía que tal principio, en sus diversas facetas, debía constituir un dique contra posibles abusos de poderes y órganos del Estado en perjuicio de la soberanía popular expresada por el Parlamento, en absoluto se hacía un discurso académico, un frío análisis á la Montesquieu sobre las buenas razones del principio de la separación de poderes, sino que se incidía en la carne viva de los dinamismos existenciales de la población.

Entonces no se podía aceptar que se siguiese hablando de la reserva de ley como un principio formal relativo nada más que a la jerarquía de las fuentes jurídicas. En efecto, el establecimiento sin excepciones de tal jerarquía era, no ya una cuestión técnica, funcional a un diagrama geométrico de tipo kelseniano para enseñar a los estudiantes, sino la certificación de una trabajosa conquista, la función protagónica del Poder legislativo, humillado durante el fascismo, que representa la sede de la 
formación dialéctica, a través de la confrontación pública, de la voluntad popular. $^{29}$

Parecidamente, tampoco la taxatividad de los preceptos y las sanciones podía ser reputada más como una suerte de invitación al legislador a escribir normas claras en pro de una exigencia de limpieza conceptual, como si la pureza del lenguaje fuese la cuestión central. No, había que considerarla un principio constitucional con plenos títulos, además de ser funcional para una garantía fundamental de los coasociados, la de poder entender con claridad el deslinde entre lo lícito y lo ilícito - y cuáles son las consecuencias del último-. ${ }^{30}$

En cuanto a la irretroactividad, el campo de batalla eran los fenómenos de retroactividad oculta y, por otro lado, la afirmación del principio según el cual no sólo el precepto y la sanción deben preexistir al hecho, sino que lo mismo ha de valer para todas las disposiciones capaces de incidir en la libertad personal, aunque su naturaleza sea estrictamente procesal.

\section{La emersión del principio de ofensividad.}

En vista de todo esto, el frente más revolucionario que abrió la reflexión penal de vanguardia en aquellos años fue ciertamente el del principio de ofensividad.

En la base de este principio existe una observación casi trivial, esto es, que para que un hecho pueda ser previsto como delito, debe resultar lesivo de un interés jurídicamente significativo, cuya naturaleza viene modelada, según el contexto histórico y geográfico, como un interés subjetivo, un bien jurídico o en términos de daño social.

El salto cualitativo que dio la doctrina italiana - mejor dicho, una parte de ella- consiste en dos pasajes que, en general, no tienen correspondencia en el ámbito comparado, tanto que se puede decir que el principio de ofensividad, así como lo plantea el modelo "fuerte" que ahora describiré,

29 Así, en una apelación al valor político del principio de reserva absoluta de ley, con una advertencia crítica contra la posibilidad de conceder el papel de fuentes penales a normas secundarias, dictadas por el ejecutivo por razones de eficiencia del sistema, BRICOLA, F., SGUBBI, F. Y MAZZACUVA, N.: Dispensa per il Corso di Istituzioni di Diritto penale. Bologna, 1994. pp. 134 s.

30 Extrajo las debidas consecuencias en un amplio trabajo monográfico PALAZZO, F.: Il principio di determinatezza nel Diritto penale. CEDAM, Padova, 1979. pp, 25 ss. 
es un "producto típico" de la ciencia penal italiana ${ }^{31}$ afirmación respaldada por el hecho de que el propio término no admite traducciones satisfactorias cuando se lo cita en otros idiomas ni halla una idéntica correspondencia conceptual en otros ordenamientos.

Con efecto, en Italia, por una parte, mediante una interpretación sistemática de los principios penales de la Constitución, se piensa que se trata, no de un principio meramente programático, sino de un vínculo normativo de primera jerarquía, que exige al legislador construir tipos penales sólo respecto de conductas idóneas para lesionar o poner en peligro bienes jurídicos -lo que excluye meros modos de ser, manifestaciones de disidencia, intenciones criminales que distan de concretarse en actos, etc.-, pero con una importantísima especificación, a saber, que los bienes objeto de la tutela deben ser bienes de relieve constitucional o esenciales, por previsión expresa o implícita de la Constitución, en la configuración de los valores de referencia de nuestro contexto social.

Por otra parte, apoyándose en una particular interpretación del inciso segundo del artículo 49 del Código penal — sobre el que pronto volveré-, una parte de la doctrina ha sostenido la tesis de que no debe ser considerado punible un hecho que corresponde en abstracto a la descripción de un tipo penal, cuando en concreto no resulte ofensivo del bien jurídico tutelado - la llamada "teoría de los hechos inofensivos adecuados al tipo"-.

Ninguna de estas dos concepciones, ambas en la base del modelo "fuerte" del principio de ofensividad, ha disfrutado de consenso unánime, pese a ser significativo el número de estudiosos que las sostienen.

Las dudas de los escépticos se refieren al hecho de que del texto de la Constitución no se deduciría con seguridad un catálogo de bienes merecedores de sanción penal, y al hecho de que la interpretación del artículo 49, inciso segundo, que da lugar a la teoría de los hechos inofensivos adecuados al tipo, sería algo forzada y, por tanto, no es preferible respecto de otra interpretación que relacione esta disposición con la regulación de la tentativa.

31 Cfr. DONINI, M.: "Il principio di offensività. Dalla penalistica italiana ai programmi europei". En: Diritto penale contemporaneo, 4/2013. pp. 4-5: "El principio de ofensividad es el elemento más original y característico de la orientación constitucional italiana hacia el Derecho penal". Inmediatamente después, el autor advierte que, en todo caso, se trata de un principio en eterna espera de realización. 


\section{La teoría de los bienes jurídicos de relevancia constitucional.}

La teoría de los bienes jurídicos de relevancia constitucional como único legítimo objeto de tutela penal fue planteada por Bricola al interior de un discurso político general dirigido a dotar al Derecho penal de filtros selectivos, necesarios a causa de su naturaleza de instrumento violento que agrede la libertad personal, y, además, pensando en un pasado no lejano en que el Derecho penal italiano se había prestado a operaciones de represión de la disidencia y el descontento social o de la afirmación de una ideología o religión.

Se observó que la Constitución republicana explicita una serie de derechos y libertades, y funda una serie de valores conexivos que cada coasociado ha de ver protegidos por el ordenamiento, incluso con el empleo de la medida extrema de una conminación penal, si así lo justifica la defensa del entramado ordenador del Estado de Derecho.

Por otra parte, hay también bienes merecedores de tutela penal que no hallan mención expresa, pero que son directamente funcionales a la afirmación de los bienes explícitos, o representan una evolución histórica de intereses que eran menos relevantes o no se los consideraba todavía cuando la Constitución entró en vigencia, no obstante, lo cual son expresión de su espíritu. ${ }^{32}$

Pues bien, las normas penales que no se dirigen a la tutela efectiva de estas categorías de bienes deben ser consideradas constitucionalmente ilegítimas, al paso que los bienes no pertenecientes a dichas categorías pueden tranquilamente hallar protección a través de las sanciones propias de otras ramas del ordenamiento jurídico.

Esta manera muy rigurosa de entender la idea de extrema ratio tropezó con objeciones ligadas, no tanto a la cuestión de principios, sino a la posibilidad objetiva de tal teoría de traducir una directriz en verdad

32 Cfr. BRICOLA, F.: "Tecniche di tutela penale e tecniche alternative di tutela". En: Funzioni e limiti del Diritto penale. Alternative di tutela, al cuidado de De Acutis y Palombarini. CEDAM; Padova, 1984. pp. 3 ss., ahora en Scritti di Diritto penale, al cuidado de S. Canestrari y A. Melchionda, vol. I, tomo II. 1997. p. 1505. 
vinculante para el legislador, ${ }^{33}$ así como a la potencial consecuencia de establecer un no deseado deber de tutela penal para los bienes en palabra. ${ }^{34}$

La desconfianza que anima la primera objeción ciertamente que no carece de motivos de cara a la realidad de los hechos, esto es, la experiencia de una práctica legislativa desbordante en número y de calidad a menudo desatenta a la extrema ratio. En efecto, la teoría del bien jurídico como elemento selectivo, si bien recibe el homenaje de un saludo formal, en muchos casos no ha podido impedir la aparición de normas de características meramente subjetivistas, moralizantes o simbólicas, o que sancionan conductas sumamente anticipadas respecto de la lesión o peligro de un interés materialmente relevante.

Hay que reconocer, pues, que el principio no es fácil de realizar - en todo caso, al final veremos que en el último tiempo el cuadro es menos hosco de como se lo presenta a veces - por diversas razones que no podemos profundizar aquí, salvo hacer una brevísima alusión al hecho de que el mainstream de los últimos dos decenios invoca una proliferación descontrolada del Derecho penal al servicio de fáciles y gratuitos consensos electorales, ${ }^{35}$ merced a la adhesión acrítica a movimientos ideológicos que

33 Esta es la tesis de fondo, recalcada algún tiempo atrás, resumiendo ese debate del siglo pasado, en el pamphlet de FIANDACA, G.: Sul bene giuridico. Un consuntivo critico. Giappichelli, Torino, 2014, y últimamente, FIANDACA, G.: Prima lezione di Diritto penale. Editori Laterza, Bari-Roma, 2017. pp. 45 ss. Extremamente condensado, el punto de vista de este importante autor es que el principio de ofensividad, entendido - lo subrayo - en su declinación fuerte, de hecho no ha funcionado como criterio vinculante de legitimación del Derecho penal, el bien jurídico no orienta en verdad al legislador, la Corte constitucional no recurre a él por el temor de ganarse la acusación de ser una suerte de peligroso legislador en las sombras, carente de legitimación democrática; en cuanto al juez ordinario, es bueno que no recurra a él para evitar incurrir en violaciones del principio de legalidad, reescribiendo por su cuenta y gusto las normas. Luego veremos que algunas de estas observaciones pueden ser objeto de réplica.

34 Sobre este aspecto, sobre todo, PULITANÒ, D.: "Obblighi costituzionali di tutela penale?". En Rivista italiana di Diritto e procedura penale, 1983. pp. 484 ss.

35 Se trata del llamado "populismo penal", del cual hay ya una vasta e interesante bibliografía. Indico, por todos, FIANDACA, G.: "Populismo giuridico e populismo giudiziario". En: Criminalia, 2013. pp. 95 ss.; PULITANÒ, D.: Populismi e penale. Sulla attuale situazione spirituale della giustizia penale, ivi, págs. 123 ss.; BRUNELLI, D.: "Il disastro populistico". En: Criminalia, 2014. pp. 254 ss., y, últimamente, con un ensayo de más largo fiato, FALCINELLI, D.: "Dal Diritto penale "emozionale" al diritto penale "etico". Il garantismo costituzionale contro l'illusione di giustizia del populismo penale". En: Anastasia, S., Anselmi, M. y Falcinelli, D.: Populismo penale: una prospettiva italiana. CEDAM, Milano-Padova, 2015. pp. 21 ss. Sobre sus bases político-filosóficas, es de sumo interés la reciente contribución de ZIZEK, S.: La tentazione populista, en H. Geiselberger, La grande regressione. Quindici intellettuali da tutto il mondo spiegano la crisi del nostro tempo. Feltrinelli, Milano, 2018. pp. 221 ss. 
propagan el control en custodia de las personas marginadas socialmente como medio de reafirmación de la ley y del orden.

En cuanto al temor de la instauración de deberes constitucionales de tutela, se ha demostrado sin gran dificultad que la relación directa del temor con la teoría constitucional del bien jurídico sólo puede ser fruto de un salto lógico inadmisible, ya que en parte alguna la teoría excluye que el legislador tiene la libre opción de sancionar con pena o con instrumentos extrapenales la lesión de ese tipo de bienes, y en algunos casos, como la tutela del honor, se incentiva el empleo de los últimos. ${ }^{36}$

\section{$X$. La crisis del principio de ofensividad ligado a la teoría constitucio- nal del bien jurídico y posibles escenarios alternativos.}

Si estos son los datos de hecho, hay que preguntarse si el deber ha de plegarse a este ser, resignándose ante la imposibilidad de limitar de algún modo los excesos expansivos del legislador, o si es acaso posible formular en hipótesis alternativas más eficientes.

\section{El escenario de la resignación.}

La primera opción, que en el fondo está aún ligada a la ideología del tecnicismo jurídico, admite de hecho que el legislador penal está libre de contenidos vinculantes y, por tanto, puede declarar como delito la conducta que fuere, con tal que sean respetados los principios de legalidad y culpabilidad, además de un genérico canon de proporción, todo ello al reparo de cualquier control de constitucionalidad.

El desencanto que anima a quien sostiene este punto de vista es comprensible; pero creo que quien ha escogido el camino de la investigación científica y la enseñanza universitaria, o sea, la formación de jóvenes juristas y ciudadanos, tiene el deber de no adaptarse a la cómoda constatación de que no hay nada que hacer $\mathrm{y}$, al contrario, debe por lo menos dar un testimonio intelectual que advierta sobre los graves riesgos de aquella actitud, suponiendo que nos importen los fundamentos del Estado de Derecho.

36 Así, respondiendo directamente al citado estudio de Pulitanò, el propio BRICOLA, F.: "Tecniche di tutela penale e tecniche alternative di tutela": En De Acutis, M. y Palombarini, G.: Funzioni e limiti del Diritto penale. Alternative di tutela. CEDAM, Padova, 1984, ahora en BRICOLA, F., Scritti di diritto penale, vol. I, tomo II, 1997. pp. 1495 ss. 
Por otra parte, agrego que me parece ilusoria la referencia de la actitud resignada a la salvaguarda de los principios de reserva de ley, retroactividad, culpabilidad y proporción, dado que, si se mira bien, como el edificio de los principios penales de garantía no está compuesto por entidades aisladas entre sí, esos principios perderían buena parte de su significado con una mengua del valor de la ofensividad.

En cambio, si nos planteamos el desafío de posibles alternativas al modelo fuerte de ofensividad basado en la teoría del bien jurídico de relieve constitucional como fundamento de legitimación del Derecho penal, podremos ver que en el último tiempo la doctrina ha ofrecido dos tipologías de criterios que cabe considerar, los que invocan el modelo funcionalista y el harm principle de elaboración anglosajona.

\section{El escenario del funcionalismo.}

Ideológicamente, el funcionalismo niega toda relevancia al concepto de bien jurídico, puesto que atribuye al Derecho penal el papel de confirmar y estabilizar la validez de las normas del ordenamiento; ${ }^{37}$ sin embargo, esta premisa da lugar a un círculo autorreferente que excluye radicalmente la posibilidad de todo discurso crítico, a cambio de lo cual puede destapar un Derecho penal del enemigo, ${ }^{38} \mathrm{y}$, en todo caso, evita plantearse problemas de legitimación, por lo que tampoco piensa en poner freno alguno a cualquier modelo de política penal que, coûte que coûte, precava la defraudación de expectativas sociales.

\section{El escenario del harm principle.}

Mientras el modelo funcionalista no ha cosechado consenso en la doctrina italiana, ${ }^{39}$ despierta gran interés en los últimos años la doctrina

$37 \quad$ Entre los penalistas, este modelo de referencia se encuentra muy bien explicado, por ejemplo, en JAKOBS, G.: Strafrecht, Allgemeiner Teil, III Aufl. Berlin, 1990. pp. 34 ss.

38 Evolución evidente, una vez más, en el decurso de Günther Jakobs (véase, entre muchas obras suyas sobre el punto, "Das selbstverständnis der Strafrechtswissenschaft vor der Herausforderung der Zukunft". En: Eser, A., Hassemer, W. y Burkhardt, B.: Die deutsche Strafrechtswissenschaft vor der Jahrtausendwende, München, 2000. pp. 47 ss.

39 Entre muchas otras contribuciones, se puede ver como ejemplo válido de la reacción suscitada en Italia los reunidos en el volumen cuidado por GAMBERINI, A. y ORLANDI, R.: Delitto politico e Diritto penale del nemico. Monduzzi, Bologna, 2007, con participación, entre otros, de Carlo Galli, Tullio Padovani, Massimo Donini, Giovanni Fiandaca, Domenico Pulitanò, Gaetano Insolera, Giuseppe Losappio, Antonio Cavaliere, 
del harm principle,$^{40} \mathrm{o}$ principio del daño, en que algún autor divisa un instrumento más adecuado que el bien jurídico para servir como criterio de limitación del Derecho penal, atendida la mayor concreción de este principio.

En resumen, la idea de un Derecho penal vinculado a la punición de conductas que provocan un daño a otros parece más funcional al respeto del principio que subyace a nuestra exigencia de ofensividad, habida cuenta de la mayor precisión con que este parámetro puede fundar ciertos límites. ${ }^{41}$

Ciertamente que así sería si es que en verdad la construcción de Feinberg, que para todos los efectos es una teoría sobre el límite entre Derecho y moral, se apoyase exclusivamente - en la mejor tradición filosófica de estampa utilitarista, que se remonta a John Stuart Mill — en la idea del daño a otros como límite irremontable de la intervención del Derecho penal. Sin embargo, profundizando su estudio, se advierte que, en una posición en parte heterodoxa respecto del riguroso liberalismo de Mill, esta construcción, junto al harm principle, admite bajo ciertas condiciones también el offense principle, bastante más elástico a la hora de reconocer la legitimidad de un Derecho

Roberto Kostoris y Emanuela Fronza. Por otra parte, es peculiar la posición crítica de TRAPANI, M.: "Guerra e diritto penale. Sull'adeguatezza degli strumenti penalistici nei confronti del c.d. terrorismo islámico". En AA.VV., Politica criminale e cultura giuspenalistica. Scritti in onore di Sergio Moccia, ob. cit., pp. 253 ss., quien reprocha al modelo de Jakobs un exceso de garantismo, en cuanto, en todo caso, funda la reacción al enemigo en el esquema penal, el que, incluso redefinido así, presenta una base de garantías, mientras que el instrumento que habría que utilizar, por ejemplo, frente al terrorismo islámico, es sólo y directamente la guerra, que se substrae a todo obstáculo garantista. No menos crítica me parece la actitud de la doctrina hispanohablante. Particularmente relevantes, a mi juicio, son las contribuciones de GONZÁLEZ CUSSAC, J.L.: "El renacimiento del pensamiento totalitario en el seno del Estado de Derecho: la doctrina del Derecho penal del enemigo". En: Revista penal, 2007. pp. 52 ss., CANCIO MELIÁ, M.: “¿“Derecho penal» del enemigo?”. En: Jakobs, G. y Cancio Meliá, M.: Derecho penal del enemigo. Hammurabi, Buenos Aires, 2005. pp. 67 ss., y ZAFFARONI, E.R.: El enemigo en el Derecho penal. Ediar, Buenos Aires, 2006.

40 Nos referimos en particular a su exposición en la obra de FEINBERG, J.: The Moral Limits of Criminal Law. Oxford University Press, 1984-1988, un bien conocido e impresionante retrato en cuatro volúmenes, dedicados respectivamente al daño a otros (Harm to Others), la molestia a otros (Offence to Others), el daño a sí mismo (Harm to Self) y la conducta ilícita innocua (Harmless Wrongdoing).

41 Este punto de vista está muy bien representado en los estudios de FRANCOLINI, G.: Abbandonare il bene giuridico? Una prospettiva procedurale per la legittimazione del Diritto penale. Giappichelli, Torino, 2014, en particular, pp. 82 ss.; FIANDACA, G.: Sul bene giuridico. Un consuntivo critico, ob. cit., y, últimamente, LAVACCHINI, M.: La legittimazione dell'intervento penale tra offensività e harm principle. Tesis doctoral, Trento, 2017, sobre todo pp. 176 ss. 
penal que castiga meras molestias y protege sentimientos, ${ }^{42}$ sin mencionar que al concepto de daño de Feinberg no son ajenos elementos paternalistas y moralistas que el concepto laico y liberal de bien jurídico no aceptaría.

Dadas estas premisas, no parce que un planteamiento semejante pueda circunscribir con mayor facilidad, con efectos ciertos y vinculantes, el perímetro de lo penalmente relevante; es más, paga un precio alto en términos de irrespeto del principio de laicidad.

Por lo demás, en este sentido hablan los hechos, antes que las opiniones.

La experiencia legislativa y judicial inglesa fue objeto de un análisis reciente muy interesante, realizado por un estudioso que enseña hace años en el Reino Unido y, por tanto, desde un observatorio privilegiado para realizar competentemente un estudio comparado.

Pues bien, el resultado de su investigación muestra cómo el harm (and offense) principle ha tenido efectos limitadores en modo alguno superiores a los que permite realizar la teoría del bien jurídico, ya que es muy consistente el número de normas penales que tutelan exclusivamente valores morales, así como son muchas las interpretaciones jurisprudenciales que basan condenas en meros modos de ser. ${ }^{43}$

42 Los que son identificables, según el pensamiento del autor, en los conceptos de molestia, embarazo, disgusto, humillación, sobresalto, irritación, alarma, inquietud, ansia, obstrucción física temporal, incomodidad, desagrado, vergüenza, nausea, aversión, situaciones que pueden estar conectadas con olores, conductas antihigiénicas o indecentes en público, manifestaciones agresivas mediante imágenes, tatuajes o escritos violentos, exhibición de objetos capaces de ofender y acompañadas de aproximaciones físicas provocadoras o indeseadas, palabras soeces, constricción a escuchar conversaciones horripilantes, desagradables, o música a alto volumen o antipática, presenciar comportamientos sexuales explícitos de variado tipo en público, exhibición de escritos racistas, antihumanitarios, antirreligiosos, etc. Véase FEINBERG, J.: Offense to Others, Oxford. University Press, 1985. p. 6, aunque condiciona la legitimidad de la intervención penal, a la relevancia de la molestia, deducida de su naturaleza, intensidad, duración, extensión y número de personas ofendidas y autores (op. cit., 35).

43 PASCULLI, Così L: “"Harm», «Offence» and "Offesa» in the english and italian criminal law. For a constitutionalisation of a unitary principle of harm in the english legal system, also as criterion of judicial interpretation". En: Diritto penale XXI secolo, 2016. pp. 316 ss. Otros estudiosos italianos que se han ocupado del tema han llegado a las mismas conclusiones. Cito solamente a DE MAGLIE, C.: "Il declino dell"harm principle". En: Politica criminale e cultura giuspenalistica, Scritti in onore di Sergio Moccia. ob. cit., pp. 443 ss., y DONINI, M.: "Danno" e "offesa" nella c.d. tutela dei sentimenti. Note su morale e sicurezza come beni giuridici, a margine della categoria dell"offense" di Joel Feinberg". En: Rivista italiana di Diritto e procedura penale, 2008. p. 1565. Tampoco en la doctrina del common law faltan voces que señalan cómo, en los hechos, el harm principle ha acabado a menudo por dar fundamento al moralismo legal y a políticas de orden, hasta el extremo de hablarse derechamente de su fracaso. Así, HARCOURT, B. E.: "The Collapse of the Harm Principle”. En: Journal of Criminal Law and Criminology, 1999. p. 181 ss. 
Tampoco parece que las cosas vayan de otro modo en Estados Unidos. Allí, digamos de pasada, han tenido difusión leyes como la de los tres strike, tan lejana de la idea del principio del daño que llega a establecer que la medida de la pena por el tercer delito (mínimo de 25 años o prisión perpetua, según el Estado) depende exclusivamente, cualquiera que fuere el delito cometido, del hecho de que el sujeto haya cometido con anterioridad otros dos de un cierto tipo. ${ }^{44}$

\section{Análisis crítico de las razones de la crisis del principio de ofensividad.}

En síntesis, no parece que sea fácil de hallar alternativas conceptuales más funcionales al principio de ofensividad. Es más, como hemos recordado, hace tiempo que el legislador italiano ${ }^{45}$ produce Derecho penal de manera expansiva y descontrolada, en una situación en que han perdido importancia, por razones que no podemos investigar aquí, formas de control y prevención social diferentes de la penalidad y, sobre todo, el propio legislador juzga que puede responder con el recurso a un Derecho penal cada vez más amplio y duro, como prima et unica ratio, a la percepción colectiva de inseguridad, que es fácilmente alimentada por los lobby del miedo.

Tenemos así, con ocasionales intervalos de tímidas y marginales providencias de despenalización, por lo común ocasionadas por meras iniciativas de deflación carcelaria, vertiginosas anticipaciones de la tutela, incriminaciones o agravantes basadas en modos de ser, referencia a la tutela de meras funciones administrativas, imposición de puntos de vista morales sostenidos en la amenaza de años de reclusión, todo ello con referencia, implícita o explícita, al omnicomprensivo bien jurídico de la seguridad. ${ }^{46}$

$44 \quad$ Para profundizar sobre el punto, véanse DELLA BELLA: "Three strikes and you're out: la guerra al recidivo in California e i suoi echi in Italia". En: Rivista italiana di diritto e procedura penale, 2007. p. 832 ss., y FORNASARI, G. y PESCE, F.: "Il legislatore alla scuola della razionalità (tra luci e ombre). Il modello di analisi economica del Diritto penale applicato ad alcune esperienze legislative": En: Indice penale, 2016. p. 421 ss.

45 En verdad, no sólo el nuestro, pero no es mi intención consolarme con aquello de mal de muchos.

46 Prescindiendo de las incongruencias de que hablaremos dentro de poco, en esta referencia se anida una paradoja singular: según datos oficiales, periódicamente publicados por el Ministerio de Justicia y el Ministerio del Interior (consultables mediante un rápido clic en internet y no desmentidos por los vértices políticos), hace varios años, especialmente los últimos, que en Italia están en evidente disminución los delitos violentos (319 fueron los homicidios dolosos en 2017, frente a los 36.000 en Estados Unidos y 50.000 de Brasil, cuyas poblaciones son sólo de 3 a 5 veces la italiana), pero a esto hace escolta un crecimiento exponencial de la percepción de inseguridad en que insiste el Gobierno, cuyas oficinas ministeriales informan cifras que la privan de fundamento (pero tratando de esconderlas al público masivo). 
Sin embargo, la seguridad, según el esquema lógico del contrato social, es acaso la propia esencia que origina al Derecho penal, no ya un bien jurídico en el sentido de la tradición penalista liberal, ${ }^{47}$ quedando la impresión de que interpretarla como tal esconde en realidad la aspiración, verdadera o simulada, de una sociedad sin riesgos, lo que constituye no sólo una utopía, sino una de las utopías más inquietantes, como bien ha recordado una estudiosa del calibre de Mireille Delmas-Marty. ${ }^{48}$

Sin embargo, esta masa de datos desalentadores no debiera cerrar la puerta al intento de volver a proponer, así sea en una fase de crisis de la sociedad y del Estado de Derecho, una visión fuerte del principio de ofensividad, como dique contra el proceso de licuefacción de ese sistema de garantías que representa el único límite que puede hacer tolerable la violencia de la intervención penal en un ordenamiento que se pretende liberal, esto es, fundado en la libertad ${ }^{49}$.

En el plano cultural, este intento disfruta de cierto precedente de no poca importancia, amén de exitoso.

Me refiero a que ningún principio constitucional en materia penal, substancial o procesal, ha conseguido afirmarse rápidamente y sin oposición. En todo caso, la larga y paciente espera ha sido finalmente premiada, como es el caso, a mi juicio paradigmático, del principio de culpabilidad.

El premio fue una fundamental sentencia de la Corte Constitucional, que se atrevió a acoger una idea de parte de la doctrina y jurisprudencia, las que habían lidiado contra una interpretación del primer párrafo del artículo 27 de la Constitución - "La responsabilidad penal es personal"- que, de

47

Esta afirmación es demostrada ejemplarmente por CAVALIERE, A.: "Può la 'sicurezza' costituire un bene giuridico o una funzione del diritto penale?": En Critica del Diritto, 2009. pp. 43 ss.

48 Cfr. DELMAS-MARTY, M.: Aux quatre vents du monde. Petit guide de la navigation sur l'océan de la mondialisation. SEUIL, Paris, 2016. p. 9.

Sostiene provocadoramente PRITTWITZ, C.: "Società del rischio e Diritto penale". En Foffani, L. y Stortoni, L.: Critica e giustificazione del Diritto penale nel cambio di secolo. L'analisi critica della Scuola di Francoforte. Giuffré, Milano, 2004. ob. cit., pp. 375 ss., que enfrentamos un proceso de expansión en que un comportamiento determinado empieza a ser criminalizado, no porque se lo estime socialmente inadecuado en sí, sino, precisamente, para que se lo considere socialmente inadecuado.

49 Este es el sentido profundo de toda la enseñanza de Luigi Ferrajoli, eficazmente compendiado en una contribución reciente que actualiza su cabida confrontándolo con los nuevos desafíos que lo ponen en peligro. Cfr. FERRAJOLI, L.: "Il paradigma garantista. Per una risposta razionale ai problemi della sicurezza e del terrorismo". En: AA.VV, Politica criminale e cultura giuspenalistica. Scritti in onore di Sergio Moccia, ob. cit., pp. 137 ss. 
hecho, lo privaba de significado con la suposición de que allí se prohíbe en materia penal nada más que la responsabilidad por hechos ajenos. ${ }^{50}$

Con la sentencia número 364 , de $1988,{ }^{51}$ la Corte valoró una orientación de la jurisprudencia de mérito, avalada sólo en algún caso por la Corte de Casación, que, limitada en un principio a casos de faltas y luego esporádicamente extendida a los delitos, sorteaba el obstáculo normativo del artículo 5 del Código penal - según el cual "nadie puede invocar como excusa la ignorancia de la ley penal"- en casos en que aparecía evidente la absoluta inexigibilidad del conocimiento de la norma violada, con una referencia al principio de buena fe, de gran relevancia en el Derecho civil, pero ajeno a los cánones interpretativos del juez penal. ${ }^{52}$ Por otra parte, la Corte valoró el gran esfuerzo de la doctrina que había captado el sentido de dicha jurisprudencia y hace tiempo invocaba el reconocimiento del carácter exculpante del error o la ignorancia inculpables..$^{53}$

La confusión que reinaba en la doctrina y jurisprudencia antes de este fallo, no impidió que tras él toda la experiencia jurídico-penal italiana recibiese definitivamente el valor constitucional del principio de culpabilidad, que la Corte empleó como fundamento de su relectura del artículo 5 del Código, en el sentido de admitir el carácter exculpante del error o la ignorancia no debidos a culpa. Con todo, aún más importante es que el fallo fue el punto de partida de una nueva sensibilidad, que, por una parte, indujo al legislador a reformar normas del Código no

50 En este sentido, NUVOLONE, P.: "Norme penali e principi costituzionali". En: Giurisprudenza italiana, 1956. p. 1253.

51 Corte Cost., 23 de marzo de 1988, n. 364, en Foro italiano, 1988, I, pág. 1385, con comentario de G. Fiandaca.

$52 \quad$ Por citar un par de sentencias significativas de esta orientación, menciono entre los fallos de fondo, Pret. Padova, 21 de diciembre de 1975, en Temi, 1976, pág. 469; Trib. Pisa, 2 de febrero de 1982, en Rivista italiana di Diritto e procedura penale, 1982, pág. 1630, Trib. Milano, 12 de febrero de 1986, en Rivista italiana di Diritto e procedura penale, 1987, pág. 449; entre las de casación, Cass., 7 de diciembre de 1963, en Cassazione penale, 1964, pág. 497, y Cass., 12 de febrero de 1981, en Rivista penale, 1981, pág. 838.

$53 \quad$ Fundamental en este sentido, la obra monográfica de PULITANÒ, D.: L'errore di Diritto nella teoria del reato. Giuffré, Milano, 1976, passim, y, con particular referencia al influjo de la jurisprudencia de la "buena fe", FORNASARI, G.: "Buona fede e delitti: limiti normativi all'art. 5 c.p. e criteri di concretizzazione". En: Rivista italiana di diritto e procedura penale, 1987. pp. 449 ss. 
respetuosas del principio y, ${ }^{54}$ por otra, indujo a la jurisprudencia a orientar su labor interpretativa, en la incertidumbre de varias soluciones, según interpretaciones conformes con aquél. ${ }^{55}$

\section{Las bases de una nueva proposición del valor del principio de ofensividad.}

Ahora, la frecuente observación de que la jurisprudencia italiana tiende a ignorar el principio de ofensividad puede hoy ser discutida si examinamos atentamente la reciente actividad tanto de la Corte de Casación como de la Corte Constitucional, ambas cada vez más proclives, la primera, a valorar la concreción de la ofensa al bien jurídico en conductas que se adecuan en abstracto a un tipo penal, la segunda, a medir la legitimidad constitucional de las normas penales con el rasero de este principio.

A quien observa que, incluso si se reconociese esta realidad, se trata de casos no frecuentes, ${ }^{56}$ es fácil replicar que el valor de un principio ordenador no debe ser medido según la cantidad de casos en que es invocado.

Creo que este argumento es intuitivo: si se razonase según el punto de vista que criticamos, entonces habría que restar significativamente valor a principios constitucionales que, pienso, a nadie se le ocurre discutir, como el de taxatividad, que figura de manera directa como motivo de abrogación de normas penales en un número de casos que se cuenta con los dedos de una mano; sin mencionar la conquista acaso más importante que debemos a la jurisprudencia constitucional, esto es, la afirmación

$54 \quad$ Para dar un ejemplo, con una ley de 1990 se modificó el artículo 59 del Código penal, que preveía la aplicación objetiva de todas las circunstancias agravantes, o sea, prescindiendo de la existencia de dolo o culpa en el sujeto.

55 Un ejemplo interesante es el del homicidio preterintencional, delito previsto en el artículo 584 del Código penal, del que por mucho tiempo se ha discutido si el resultado de muerte que siguió a las lesiones o golpes dolosos se ha de imputar objetivamente (así, por todos, ZUCCALÀ, G.: Il delitto preterintenzionale. Priulla, Palermo, 1952. p. 42) o, en cambio, siempre y cuando hubiese culpa (en este sentido, FIORELLA, A.: "Responsabilità penale". En: Encicolpedia del Diritto, vol. XXXIX. Giuffré, Milano, 1988. p. 1321), tesis acaso minoritaria antes de la sentencia de la Corte constitucional sobre el artículo 5, pero hoy absolutamente prevalente.

56 Así, por ejemplo, PALIERO, C. E.: "Sicurezza dei mercati o mercato delle (in)sicurezze?". En Donini, M. y Pavarini, M.: Sicurezza e Diritto penale. Bononia, University Press, Bologna, 2011. pp. 302 ss. 
del principio de culpabilidad, hoy columna indiscutida, pero cuyas aplicaciones por los tribunales ordinarios son de número modesto, como era de prever.

\section{La teoría de los hechos inofensivos adecuados al tipo.}

Antes de pasar revista a algunas de las decisiones más significativas de ambas Cortes, con la que querría demostrar la falta de fundamento de la tesis de que éstas se desinteresan del principio de ofensividad, es necesario anteponer una premisa histórico-conceptual obvia para el lector italiano, pero no para quienes carecen de un conocimiento profundizado de la historia penal de mi país.

La premisa es importante, porque allí donde la jurisprudencia muestra su voluntad de valorar la idea de la ofensividad, ha acogido un punto de vista doctrinal, sostenido por una minoría de estudiosos, que atribuye a una norma penal, en apariencia secundaria, un papel fundamental en nuestro sistema penal, identificando en ella la existencia de hechos inofensivos (por tanto, no merecedores de pena), pese a adecuarse a un tipo criminoso.

La norma objeto de esta disputa es el artículo 49, inciso segundo, del Código penal, que regula el llamado delito imposible, y reza así: "Asimismo, ${ }^{57}$ la punibilidad se excluye cuando la inidoneidad de la acción o la inexistencia de su objeto tornan imposible el resultado dañoso o peligroso". Hay que recordar, también, que el cuarto inciso del mismo artículo faculta al juez, en caso de delito imposible, para someter al inculpado absuelto a una medida de seguridad (la libertad vigilada, que es la menos invasiva de todas las que afectan a la libertad personal).

El punto debatido es la referencia a la inidoneidad de la acción.

Por una parte, tradicionalmente, se afirma que cuando la norma establece la no punibilidad si la acción no es idónea, no hace sino trazar el anverso de la disposición sobre la tentativa (que, a su turno, para la punibilidad requiere la idoneidad del acto) $;{ }^{58}$ pero ello no sería del todo superfluo,

$57 \quad$ Este adverbio (“altresì, en italiano) relaciona el precepto con la regulación del inciso precedente, que, a su vez, establece la no punibilidad del delito putativo.

58 Art. 56, inciso 1, del Código penal: "Responde de delito tentado quien realiza actos idóneos y dirigidos inequívocamente a cometer un delito, si la acción no se completa o el resultado no se produce". 
porque es funcional a la previsión de la medida de seguridad aplicable al imputado absuelto, pero socialmente peligroso. ${ }^{59}$

Por otro lado, hay quienes asignan a la disposición, en lo que respecta la inidioneidad, un papel mucho más relevante y, en la vía de la concepción "realista" del delito, piensan que impone la absolución del inculpado cuando quiera que su comportamiento, adecuado en abstracto a un tipo, resulte concretamente inofensivo para el bien jurídico protegido. Así, el inciso del artículo en palabra representaría la referencia del Código al principio de necesaria ofensividad del delito. ${ }^{60}$

Aparte de la insatisfacción por un planteamiento que ve en la norma una disposición repetitiva $\mathrm{y}$, en definitiva, inútil, amén de extraño emplazamiento en el Código, muy distante del artículo al que vendría a integrar, el que trata de la tentativa, esta segunda interpretación parte de algunos datos textuales y sistemáticos.

Por lo pronto, de una singular incongruencia, a la que da lugar la concepción tradicional, ya que el artículo 49 se refiere al "delito" reato- imposible, en un sentido amplio, de modo que debiera regular también las faltas, al contrario del artículo 56, que habla expresamente de "delito" - delitto- en sentido estricto, por tanto, incompatible con las contravenciones. ${ }^{61}$ De ello se seguiría que quien con actos idóneos intenta cometer una falta no podría sufrir pena, al paso que quien trata de cometerla con actos inidóneos correría el riesgo de sufrir una medida de seguridad, si viene considerado sujeto socialmente peligroso.

Luego, en cuanto al contenido normativo específico, se destaca que la disposición sobre la tentativa menciona la inidoneidad de los actos, mientras que la del delito imposible se refiere a la inidoneidad de la acción;

59 Ejemplificativamente, el clásico texto de ANTOLISEI, F.: Manuale di Diritto penale, Parte generale. Giuffré, Milano, 2000. p. 500, así como PAGLIARO, A.: Principi di Diritto penale, Parte generale. Giuffré, Milano, 2003. p. 421.

En este sentido se pronuncia también la jurisprudencia (últimamente, Cass., 23 de febrero de 2004, en Rivista penale, 2005, pág. 642), que considera necesaria una verificación ex ante, como en la tentativa, y acostumbra a negar la aplicabilidad de la norma sobre el delito imposible, por ejemplo, en caso de una intervención de la policía subsiguiente a un acecho preventivo (Cass., 3 de octubre de 2001, C., Guida al diritto, 2001, n. 49, 93).

60 En este sentido, todavía en el ámbito de los manuales, FIORE y FIORE, Diritto penale, Parte generale, ob. cit., p. 319.

61 Que en Italia son castigadas sólo en su forma consumada, no en grado de tentativa. 
y estos dos conceptos no son sinónimos, porque la acción comprende, semánticamente, los actos. ${ }^{62}$

Por ende, aquí se regula, no formas particulares de tentativa, sino una acción terminada y correspondiente a la que el tipo describe, pero que es imposible que produzca el resultado dañoso o peligroso, entendido como ofensa concreta al bien jurídico tutelado, por cuanto la acción no fue idónea para producirlo.

Esta concepción alternativa del delito imposible, que parte del presupuesto de la existencia de hechos inofensivos adecuados al tipo, ha hallado cierta acogida no sólo en la doctrina, sino en la jurisprudencia, tanto común como constitucional, ${ }^{63}$ aunque también tropieza con la oposición de varios estudiosos que combaten su presupuesto.

Se afirma que no habría margen alguno para que un hecho pueda ser típico y, a la vez, inofensivo. Todos los hechos típicos son ofensivos, porque, de ser verdad lo contrario, se acaba por atribuir al juez una suerte de impropio poder legislativo, subrogándole al Parlamento, si es que pudiera establecer cuáles conductas deben ser consideradas como lesivas de bienes jurídicos. ${ }^{64}$

Se agrega que los ejemplos aducidos para demostrar el supuesto divorcio de tipicidad y antijuridicidad - hurto de objetos carentes de valor, calumnia patentemente inofensiva, falsedad documental inocua o grosera- no son en modo alguno decisivos, por cuanto a la solución de la no punibilidad de estas conductas se podría añadir una argumentación que

62 A favor de esta interpretación, entre otros, NEPPI MODONA, G.: "Reato impossibile". En: Digesto delle discipline penalistiche, t. XI. Torino, 1996. pp. 259 ss., RIZ, R.: Lineamenti di Diritto penale, Parte generale. CEDAM, Padova, 2006. p. 110, GALLO, M.: Appunti di Diritto penale, vol. III, Le forme di manifestazione del reato. Giappichelli, Torino, 2003. p. 92, y CATERINI, M.: Reato impossibile e offensività. Un'indagine. Edizioni Scientifiche Italiane, Napoli, 2004, passim y, en particular, p. 374.

63 Así, por todas, en la jurisprudencia ordinaria, Cass. 9 de febrero de 2005, Rivista penale, 2005, pág. 419, Cass., 15 de mayo de 1989, Cassazione penale, 1991, pág. 572; en la constitucional, Corte Cost. 519/2000, Cassazione penale, 2001, pág. 2015, Corte Cost. 263/2000, Giurisprudenza Costituzionale, 2000, pág. 2064, Corte Cost. 333/1991, Giurisprudenza Costituzionale, 1991, pág. 2646.

64 Así, sobre todo, STELLA, F.: "La teoria del bene giuridico e i c.d. fatti inoffensivi conformi al tipo". En: Rivista italiana di Diritto e procedura penale, 1973. p. 20, MARINUCCI, G.: "Fatto e scriminanti. Note dommatiche e politico-criminali". En: Rivista italiana di Diritto e procedura penale, 1983. p. 1223, y, en los manuales, CADOPPI, A. y VENEZIANI, P.: Elementi di Diritto penale, Parte generale. CEDAM, Padova, 2015. p. 469. 
niega derechamente su tipicidad, sobre la base de una valoración judicial que muestre su referencia apenas aparente al tipo delictuoso. ${ }^{65}$

Paso por alto someramente otras objeciones, de carácter principalmente exegético y no esenciales para nuestro discurso, el que prosigo observado que no son insuperables.

A mi juicio, no hay duda que la interpretación que ve en el segundo inciso del artículo 49 un reflejo del principio de necesaria ofensividad, es más adecuada que la tradicional para atribuir sin artificios un sentido autónomo a la disposición - preservando, así, su contenido como norma-, mientras que, en lo que respecta a la relación de tipicidad y ofensividad, no parece que la solución de los defensores de la tesis tradicional asigne al juez, en los casos que ellos invocan, un papel menos protagónico, ya que le confían la determinación de cuándo la tipicidad es real y cuándo aparente, sin indicarle criterios unívocos de elección. Esta postura no representa una ganancia significativa en términos de legalidad. ${ }^{66}$

Por ende, me parece preferible separar la suerte del delito imposible de la del delito putativo, e interpretar la disposición glosada como una norma que confía al juez, según una comprobación ex post (asimilable a la comprobación de la causalidad, pero distinta de la que ex ante caracteriza la indagación de la idoneidad de los actos en la tentativa), la tarea de establecer si conductas que se corresponden con tipos delictuosos previstos por la ley carecen de concreta capacidad ofensiva frente al bien tutelado. ${ }^{67}$

65 Cfr. NAPPI, A.: Guida al Codice penale, Parte generale. Giuffré, Milano, 2003. p. 291.

66 Así, también NEPPI MODONA, G.: "Il lungo cammino del principio di offensività ". En: Studi in onore di Marcello Gallo. Scritti degli allievi. Giappichelli, Torino, 2004. p. 93.

67 Por otro lado, forma parte de la realidad de las cosas el hecho de que cada vez que se construye un tipo penal, se traza un concepto descriptivo que representa un genus capaz de comprender numerosas species, y no es seguro que todas las conductas en principio reconducibles a aquel concepto sean realmente lesivas del interés jurídico tutelado con esa disposición; tanto es así, que a veces es el mismo legislador el que identifica umbrales por encima o debajo de los cuales la conducta es penada o no. Este argumento ha sido utilizado también por la Corte Constitucional en la sentencia 333 de 1991. El tema es bien profundizado en sus términos generales por D'ALESSANDRO, F.: Pericolo astratto e limiti-soglia. Le promesse non mantenute del diritto penale. Giuffré, Milano, 2012. p. 265 ss., quien recuerda cómo esta técnica sea utilizada particularmente allí donde el Derecho penal sirve para prevenir riesgos (tutela del ambiente, salud de los trabajadores, etc.). En el Código penal brinda un ejemplo demostrativo el artículo 316 ter (percepción indebida de erogaciones en perjuicio del Estado), que sanciona la conducta del que, utilizando o presentando declaraciones o documentos falsos, $\mathrm{u}$ omitiendo informaciones debidas, obtiene indebidamente diversas clases de aportes o financiamientos públicos, no obstante lo cual especifica luego que si la suma 
Esto no implica riesgos para el ajuste del sistema penal ni para el principio de legalidad, puesto que, en primer lugar, tampoco se trata de hacer una criba completa, dado que la regla es la correspondencia entre tipicidad y ofensividad, y excepcional la aplicación de la disposición sobre el delito imposible, ${ }^{68} \mathrm{y}$, en segundo lugar, la tarea del juez en este caso no va allende los límites ordinarios de su trabajo hermenéutico de traductor de los principios normativos a la solución del caso concreto. ${ }^{69}$

\section{Orientaciones recientes de la Corte de Casación en el tema de la ofensividad.}

Estas bases teórico-dogmáticas me permiten cerrar mi discurso, enunciando ahora en detalle algunas posturas de la jurisprudencia que pueden ser entendidas, a mi juicio, como señal de una sensibilidad hacia el principio de ofensividad que podría proyectarse hacia un pleno reconocimiento, con significativas implicaciones en todo el tejido de los principios que condicionan la legitimidad del empleo del Derecho penal.

Naturalmente, las modalidades con que se da importancia a la ofensividad son diferentes según se trate de la jurisprudencia ordinaria o la jurisprudencia de casación. La primera, en efecto, hace hablar al principio cuando declara sobre el fondo de los asuntos la no punibilidad de conductas típicas que aparecen inidóneas para violar el bien tutelado, apoyándose en la disposición del artículo 49, además de en la relevancia constitucional de aquél; por su parte, la segunda valora esta última dimensión como punto de apoyo para declarar ilegítimas normas vigentes.

El análisis de los recientes hallazgos jurisprudenciales de la Corte de Casación es de particular interés, porque si bien, por un lado, se refieren a veces a situaciones que representan "casos de manual", de limitada relevancia práctica, por ejemplo, cuando la Corte excluye la punibilidad de la falsedad documental inocua ${ }^{70}$ o grosera, ${ }^{71}$ con tal que sea inmediata

percibida indebidamente no supera cuatro mil euros, tampoco cumplimenta este delito (sino un simple ilícito administrativo).

68 Por lo demás, y como en el caso del principio de culpabilidad, el campo de aplicación del principio de ofensividad no puede ser sino reducido, porque, de lo contrario, se produciría de hecho la quiebra del Derecho penal. Pero, como en el caso del otro principio, esto no quita nada a su valor general como fundamental principio de cultura.

69 En el mismo sentido, también, CANESTRARI, S., CORNACCHIA, L. Y DE SIMONE, G.: Manuale di Diritto penale, Parte generale. Bologna, 2007. p. 685.

$70 \quad$ Cass., 14 de julio de 2016, n. 41167.

$71 \quad$ Cass., 24 de febrero de 2015, n. 18015. 
y fácilmente perceptible para el sujeto que debía ser engañado ${ }^{72}$ otras veces se sale de estos casos obvios y la declaración de no punibilidad se refiere a situaciones que conciernen a los más dispares bienes jurídicos y caracterizadas por una dimensión práctica en absoluto irrelevante.

Una reciente sentencia de la Corte, con efecto, ha declarado que para que se configure el delito de cultivo de plantas estupefacientes no basta con el establecimiento de la conformidad de éstas con el tipo botánico prohibido, debiéndose establecer, además, la ofensividad concreta de la conducta, entendida como la capacidad efectiva y actual de la substancia obtenida u obtenible de producir un efecto estupefaciente y como concreto peligro de aumento de su disponibilidad y ulterior difusión. La sentencia anuló una de la Corte de Apelaciones de Florencia, que había condenado al imputado por el cultivo de una planta de cannabis indica de la que se obtuvo 0,345 gramos de principio activo. ${ }^{73}$

Otras aplicaciones interesantes de la disciplina del delito imposible surgen recientemente a propósito de los delitos contra la Administración de Justicia, de manipulación del mercado, corrupción y publicación arbitraria de actas de un proceso penal. ${ }^{74}$

El primero es un caso de evasión impropia (artículo 385, inciso 3, del Código penal), en que la Suprema Corte anula una condena de la Corte de Apelaciones de Messina, considerando no responsable del delito a un sujeto que, hallándose en detención domiciliaria, se había alejado un centenar de metros de la casa a la espera de los Carabineros, quienes, a su ruego (motivado por un furibundo litigio con la consorte), debían reconducirlo a la cárcel. ${ }^{75}$ En la fundamentación del fallo se afirma que tal conducta carece de ofensividad concreta según el artículo 49, inciso segundo, del Código,

72 Para esta importante precisión en materia de falsedad ideológica, pero con valor general, cfr. Cass., 6 de diciembre de 2012, n. 5687.

73 Cass., 17 de febrero de 2016, n. 8058. Idéntico principio había sido afirmado en situaciones análogas en Cass., 21 de octubre de 2015, n. 2618, Cass., 10 de noviembre de 2015, n. 5254, Cass., 11 de diciembre de 2014, n. 9156, Cass. 8 de abril de 2014, n. 33835.

$74 \quad$ Frente a la frecuente observación crítica de que los casos inofensivos, amén de no ser muchos, corresponden sólo a ilícitos de poco peso, la lista del texto brinda un parcial desmentido; pero, por otra parte, es evidente que la propia noción de hecho inofensivo no puede normalmente referirse a delitos de notable gravedad (es difícil pensar en un homicidio, unos estragos, robo o violación inofensivos), sin olvidar que éstos son casos estadísticamente modestos en la vida judicial cotidiana.

75 Cass., 6 de octubre de 2015, n. 44595, en Giurisprudenza Italiana, 2016, pág. 189 , con nota de adhesión di G. Fornasari, Evasione impropria, principio di offensività e reato impossibile. 
porque el imputado nunca pretendió substraerse al control de la autoridad, de modo que el bien jurídico protegido por el delito que castiga la evasión, esto es, la exigencia de garantizar el respeto de las decisiones emitidas por la autoridad judicial, ${ }^{76}$ no fue lesionado ni puesto en peligro.

El segundo caso concierne al tipo de difusión de noticias falsas e idóneas para provocar una alteración del precio de instrumentos financieros - artículo 185 del Decreto legislativo número 58, de 1998-. Aquí la propia norma requiere que el juez verifique la idoneidad concreta del comportamiento realizado por el agente, de provocar efectos distorsivos en el mercado financiero; pero, además, la Corte de Casación considera necesario, en obsequio del principio de concreta ofensividad, el establecimiento contra fáctico ex ante de los efectos que habría producido en el mercado la eventual difusión de la noticia verdadera, con la consiguiente exclusión de la responsabilidad si fuese presumible que ésta habría tenido las mismas consecuencias de la falsa. ${ }^{77}$

El tercer caso es una vicisitud jurisprudencial del delito de cohecho, y se caracteriza porque el proceso concluyó con la condena de los imputados; sin embargo, al fundamentar su decisión, la Corte traza una interesante actio finium regundorum, fijando el principio sobre el cual se habría debido aplicar la disciplina del delito imposible, con la consiguiente absolución, cuando quiera que la promesa del funcionario público, aceptada por el particular, se refiera a un acto o comportamiento que parezca de imposible verificación según un juicio ex ante. ${ }^{78}$

Desde el punto de vista de la riqueza de la fundamentación, la sentencia más interesante es también la más reciente y autorizada, ya que proviene del pleno de la Corte.

En un caso de publicación arbitraria de las actas de un proceso penal artículo 684 del Código-, el pleno de la Corte de desentiende completamente de la cuestión de la tipicidad o atipicidad de la conducta, considerándola de poca relevancia práctica, y va derechamente al corazón del problema con la inequívoca mención del papel del principio de ofensividad como canon interpretativo unánimemente aceptado - invocando expresamente una

$76 \quad$ Así, la jurisprudencia dominante, bien ejemplificada por Cass., 16 de febrero de 1999, en Giurisprudenza Italiana, 2001, pág. 811, y, adhiriendo, la doctrina más acreditada. Cfr. BORSARI, R.: "Evasione”. En: Fornasari, G. y Riondato, S.: Delitti contro l'amministrazione della giustizia, $2^{\mathrm{a}}$ ed. Torino, 2017. p. 294.

77 Cass., 20 de junio de 2012, n. 40393.

78 Cass., 30 de enero de 2013, n. 34489. 
argumentación análoga de la Corte Constitucional), ${ }^{79}$ con la consecuencia para el específico caso de aplicación de la falta del artículo 684, de que la orientación que postula que el juez del fondo valore la entidad de la reproducción a la hora de juzgar la existencia del delito, es el punto obligatorio de llegada de la lectura constitucional y sistemática de la norma, y de que, en general, la apreciación de la idoneidad lesiva de la conducta según el principio de ofensividad se asume ya como Derecho vigente, de suerte que el juez que la lleva a cabo no viola la disciplina legislativa, sino que, al contrario, aplica debidamente un instrumento hermenéutico que debe ser considerado expresión de los principios constitucionales de los artículos 3 y 25 , inciso 2 , igualdad y legalidad. ${ }^{80}$

Hace menos todavía, el mismo pleno de la Corte, convocado a distinguir el campo de aplicación de los artículos 49, inciso segundo - delito imposibley 131 - exclusión de la punibilidad por el carácter especialmente tenue del hecho- del Código, afirma con gran claridad que el primero es expresión del principio de ofensividad, y éste, un principio general del sistema penal con fundamento constitucional en una serie de disposiciones de la Carta fundamental y dotado de un doble nivel de acción, uno abstracto, como canon de política criminal válido para el legislador en la identificación de los comportamientos de relevancia penal, y otro concreto, de criterio hermenéutico para el juez. En este segundo papel, su función consiste en vedar la configuración de los tipos penales en presencia de comportamientos concretamente inofensivos de los bienes jurídicos tutelados, contribuyendo así a definir el ser o no ser de un delito o de una circunstancia. ${ }^{81}$

\section{Orientaciones recientes de la Corte Constitucional en el tema de la ofensividad.}

La historia de la jurisprudencia constitucional en el tema de la ofensividad es compleja y confusa.

$79 \quad$ La referencia es a la sentencia Corte cost., 11 de junio de 2014, n. 172.

80 Cass. SS.UU., 25 de febrero de 2016, n. 3727.

Hace poco, sintéticamente, pero en la misma dirección, el pleno de la Corte se ha pronunciado por una visión restrictiva de la noción de destreza con respecto de la agravante del delito de hurto del artículo 625, inciso 1, número 4, del Código, con expresa referencia a la necesaria extensión del principio de ofensividad a las circunstancias del delito. Así, Cass., 12 de julio de 2017, n. 34090, en Giurisprudenza Italiana, 2017, pág. 2729, con nota de E. Corn, Il ladro temerario e il proprietario sbadato.

81 Cass. SS.UU., 6 de abril de 2016, n. 13681, en Diritto penale e processo, 2016, págs. 894 ss. 
Algunas sentencias que se remontan a los años ochenta la mencionan de pasada, sólo reconociéndole el valor de un canon interpretativo no provisto de relevancia constitucional y ligándolo nada más que al artículo 49, inciso segundo, del Código. ${ }^{82}$

En un segundo momento, entre los años noventa y el inicio del siglo XXI, se pasa a una mención directa del principio. No obstante, el factor declamatorio, se subraya su importancia y relación con el principio de legalidad constitucionalizado en el artículo 25, siquiera sin convertirlo todavía en causa directa de una declaración de ilegitimidad, ${ }^{83}$ reserva hecha de un pronunciamiento que declara inconstitucional el tipo - cierto es que muy marginal y ligado al pasado fascista - que castigaba la ostensión no autorizada de banderas extranjeras, al que se objetó ser una conducta que no lesionaba bien jurídico alguno. ${ }^{84}$

Un giro importante lo dio la sentencia que condujo a la abrogación del artículo 688, inciso segundo, del Código penal, que castigaba la embriaguez manifiesta de un sujeto anteriormente condenado por delito no culposo contra la vida o la incolumidad individual..$^{85}$

En este caso, el principio de ofensividad, al que se relaciona expresamente con el artículo 25 de la Constitución en su lazo sistemático con el conjunto

82

Así, Corte Cost., 26 de marzo de 1986, n. 62, en Giurisprudenza Costituzionale, 1986, págs. 408y ss.

83 Tenemos dos ejemplos de ello en las sentencias Corte Cost., 15 de diciembre de 1995, n. 519, respecto del delito de mendicidad, art. 670 del Código penal (en Giurisprudenza Costituzionale, 1995, pág. 4534), y Corte Cost., 2 de octubre de 1996, respecto del delito de posesión injustificada de valores, art. 708 del Código (en Giurisprudenza Costituzionale, 1996, págs. 335 ss.). Por otra parte, la primera de ellas es muy significativa, ya que la Corte, en el punto central de su argumentación, afirma que en un cuadro social cambiado, en que se atribuye valor constitucional a la solidaridad, la figura criminal de la mendicidad no invasiva parece constitucionalmente ilegítima a la luz del canon de la razonabilidad, no pudiéndose considerar en absoluto necesario el recurso a la regla penal, y que el bien jurídico de la tranquilidad pública no es ciertamente puesto en peligro por una mera solicitud de ayuda. La insistencia en la falta de peligro para el bien jurídico es todavía más significativa - como subraya, también, MANES, V.: Il principio di offensività nel diritto penale. Canone di politica criminale, criterio ermeneutico, parametro di ragionevolezza. Giappichelli, Torino, 2005. p. 227, n. 46- si se considera el hecho que en la misma sentencia la Corte ha declarado legítimo, en cambio, el segundo párrafo del art. 670, que concierne a la mendicidad invasiva, por su idoneidad para tutelar relevantes bienes jurídicos.

84 Corte Cost., 21 de mayo de 1987, n. 189, en Giurisprudenza Costituzionale, 1987, págs. 1375 ss. Por escasa o nula que sea la cabida de la norma abrogada, resulta relevante y neta la afirmación del principio por la Corte, que hace expresa referencia a la circunstancia de que el hecho típico carece de toda significación y ofensividad.

Corte Cost., 17 de julio de 2002, n. 354, en Foro italiano, 2003, I, págs. 2923 y ss. 
de valores que convergen en la dignidad humana, fue cargado con la fuerza demostrativa necesaria para fundar la declaración de inconstitucionalidad, como límite con aptitud de impedir que la condición de condenado por ciertos delitos pueda transformar en delito hechos que en otros sujetos no lo serían, esto es, conjurar una incriminación por tipos de autor. ${ }^{86}$

En el mismo surco se inserta una sentencia posterior, ${ }^{87}$ la que con argumentos semejantes y citando pasajes esenciales de la sentencia de 2002, decidió abrogar una circunstancia agravante introducida al Código en 2008, de suyo controvertida en el plano político, en cuanto implicaba un aumento de pena de cualquier delito cometido por un inmigrante irregular, por el solo hecho de su irregularidad. La abrogación fue relacionada expresamente con la violación del principio de ofensividad, cuya lesión la producía el hecho de que la agravante no se refería al bien protegido, sino sólo a destacar de manera inaceptable una general y presunta calidad negativa en su autor.

Esta sentencia causó clamor en el debate público, incluso fuera del círculo especializado; pero hay que decir que acogió un punto de vista difundidísimo entre los especialistas, si se piensa que la ley que previó la agravante había sido impulsada por el gobierno de derechas jen contra del parecer de los profesores de Derecho penal, procedimiento penal y Derecho constitucional, aunque también contra el Consejo Superior de la Magistratura, la Unión de las Cámaras penales ${ }^{88}$, el gabinete jurídico del Parlamento europeo, el Comisario de Justicia de la Unión Europea, el Alto Comisariado de la ONU para los derechos humanos y el Vaticano -la secretaría del Consejo Pontificio para los inmigrantes- ${ }^{89}$

Así y todo, hay que puntualizar que doctrina y jurisprudencia de mérito habían denunciado casi unánimemente, desde el principio, la ilegitimidad de la agravante, sólo que empleando una pluralidad de argumentos, como

86 Con razón esta sentencia es considerada como el primer ejemplo de efectiva "justiciabilidad" autónoma del principio de ofensividad. Así, SILVANI, S.: "Definitivamente estromessa dal sistema penale l'ubriachezza manifesta". En: Giurisprudenza Costituzionale, 2002. pp. 2673 ss.

87 Corte Cost., julio de 2010, n. 249, en Rivista italiana di Diritto e procedura penale, 2010, págs. 1349 ss.

$88 \quad$ Organismo que agrupa a todos los abogados penalistas.

89 La interesante vicisitud de la aprobación de la ley es bien seguida por GATTA, G.L.: "Aggravante della "clandestinità" (art. 61 n. 11 bis c.p.): uguaglianza calpestata". En: Rivista italiana di Diritto e procedura penale, 2009. pp. 713 ss. 
la violación del principio de igualdad,${ }^{90} \mathrm{del}$ principio de razonabilidad, ${ }^{91} \mathrm{del}$ principio de culpabilidad ${ }^{92} \mathrm{y}$, naturalmente, de la ofensividad, subrayando que la ofensa al bien jurídico no es más grave cuando comete el delito un extranjero de presencia irregular en el país, que cuando lo perpetra un italiano o un extranjero residente. ${ }^{93} \mathrm{La}$ Corte Constitucional fue la que hizo una opción fuerte y decidida por una valoración máxima del principio de ofensividad, ${ }^{94}$ proponiendo así un modelo que ha encontrado terreno fértil en sentencias posteriores.

En efecto, sólo cuatro años después dos sentencias de la Corte, con apenas tres semanas de diferencia la una de la otra, nivelan el campo para transformar el canon de la ofensividad, de principio argumental a principio demostrativo, como diría Massimo Donini. ${ }^{95}$

90 En tal sentido, DODARO, G.: "Discriminazione dello straniero irregolare nell'aggravante comune della clandestinità". En: Rivista italiana di Diritto e procedura penale, 2008. pp. 1634 ss., PULITANÒ, D.: "Tensioni vecchie e nuove sul sistema penale". En: Diritto penale e processo, 2008. pp. 1079 ss., y, entre los constitucionalistas, ONIDA, V.: "Efficacia non scontata per il ricorso al penale". En: Il Sole 24 ore, 22 de mayo de 2008, 7, quien, extendiendo el campo de referencias, afirmaba que la disposición "efectúa una verdadera discriminación de personas en razón de su origen nacional y condiciones personales, prohibida por los artículos 2 y 7 de la Declaración Universal, 14 de la CEDU y 26 del Pacto internacional de derechos civiles y políticos, además del artículo 3 de la Constitución".

91 GATTA, G.L.: Aggravante della "clandestinità" (art. 61 n. 11 bis c.p.): uguaglianza calpestata, ob. cit., pp. 745 ss., sobre la base de la jurisprudencia de la Corte constitucional (sent. De 27 de junio de 2008, n. 236), según la que las elecciones de política criminal del legislador no son censurables en sede de control de constitucionalidad, "a menos que se trate de opciones manifiestamente irracionales", lo que ocurre si "el legislador introdujo disparidades injustificadas de tratamiento dentro de un cuadro normativo históricamente dado", ejemplo de lo cual es que nos hallemos "ante tipos de delito substancialmente idénticos, pero sometidos a diferente tratamiento sancionatorio".

92 En efecto, la calidad de irregular del inmigrante no añade nada a la intensidad del reproche personal por el hecho cometido. Así, Trib. Ferrara, Ordinanza de 15 de julio de 2008, en Corriere del Merito, 2008, pág. 1283, uno de los tribunales que elevaron la cuestión de legitimidad a la Corte.

93 En este sentido, por todos, ALESSANDRI, A. y GARAVAGLIA, E.: Non passa lo straniero, e www.lavoce.info, 16 de junio de 2008, 2, y Trib. Latina, Ordinanza de 1 de julio de 2008, en Corriere del Merito, 2008, pág. 1175.

94 Como bien sostiene MANES, V.: "I recenti tracciati della giurisprudenza costituzionale in materia di offensività e ragionevolezza". En: Diritto penale contemporaneo, 2/2012. p. 195, el mensaje que lanza la Corte es que ante el principio de ofensividad ninguna elección o modulación sancionatoria puede ser justificada con rasgos de autor sic et simpliciter, cuando tal diferenciación subjetiva no exprese una mayor daño o peligro para el bien jurídico tutelado.

95 Me refiero a la elaboración conceptual contenida en el trabajo citado de DONINI, M.: Il principio di offensività. Dalla penalistica italiana ai programmi europei, ob. cit., p. 16. 
En la primera de ellas, a propósito del delito de omisión de enterar cotizaciones de previsión social, se brinda una precisa orientación metodológica al poner a cargo del juez la tarea de valorar si la conducta, tomando en cuenta la ratio del tipo penal, carece concretamente de idoneidad lesiva de los bienes jurídicos tutelados. ${ }^{96}$

La segunda sentencia es de particular interés, pese a que presenta la paradoja de contener afirmaciones determinantes para el destino del principio de ofensividad, pero en el marco de una decisión que no acogió la solicitud de declarar ilegítima la disposición enjuiciada.

El tipo era el de stalking - artículo 612 bis del Código-, y la solicitud consistía en abrogarla por defecto de determinación; pero la Corte, con una declaración muy general, dijo que "toca al juez reconstruir y circunscribir el área de la tipicidad de la conducta penalmente relevante, sobre la base de los cánones hermenéuticos acostumbrados, particularmente el principio de ofensividad, el que constituye, según jurisprudencia constante de la Corte y como ha recalcado también la Corte de Casación en el caso ya citado, un canon interpretativo de unánime aceptación". Para terminar, la Corte señala que, si el legislador decidiese reformar esta materia, no puede sino hacerlo respetando el principio de ofensividad, que tiene relevancia constitucional. ${ }^{97}$

\section{Corolarios de la jurisprudencia de las Cortes.}

En suma, en lo que podría parecer un obiter dictum - pero no lo es, ya que la Corte no acostumbra a entregar motivaciones recargadas inútilmente con licencias dialécticas - se fija algunos conceptos de importancia estratégica, que aquí compendio en tres proposiciones.

El principio de ofensividad, por jurisprudencia constante de entrambas Cortes, ${ }^{98}$ ha entrado en el Derecho vigente, con relieve constitucional, como canon interpretativo de unánime aceptación.

Debe ser considerada ilegítima, por defecto de ofensividad, una disposición cuya descripción típica comprende sólo o principalmente conductas - o agravantes- que no pueden lesionar un bien jurídico - en lo

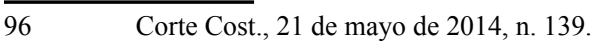

97 Corte Cost., 11 de junio de 2014, n. 172.

98 Se podría decir que aquí tenemos un caso de cross fertilisation "doméstica", dado que, a su vez, la Corte de Casacón, en las sentencias anteriormente citadas, se ha referido varias veces al reconocimiento que el principio ha recibido por parte del juez de las leyes. 
que se da a entender, implícita pero claramente, que el bien jurídico no es el objeto jurídico que se deduce del tipo mismo, según la concepción metodológica, sino una entidad de valor preexistente respecto de la norma, entidad que ha de revestir, a lo menos indirectamente, jerarquía constitucional-..$^{99}$

La jurisprudencia tiene la tarea de aplicar las normas penales cuando el tipo abstracto se preste a interpretaciones diversas, teniendo necesariamente en cuenta el carácter ofensivo de las conductas y, por tanto, haciéndose cargo del filtro del juicio de constitucionalidad. ${ }^{100}$

Por ende, estamos ante una advertencia de valor general, de respeto al principio en palabra, al que se reconoce expresamente valor constitucional, tanto para el juez que aplica la ley como para el legislador que la escribe. ${ }^{101}$

\section{Pocas luces y muchas sombras en la actitud del legislador ante el vínculo del principio de ofensividad.}

El sujeto que todavía hoy se muestra recalcitrante ante este modo de razonar que ha penetrado tan bien en la forma mentis de doctrina y jurisprudencia, no hay duda que es el legislador. ${ }^{102}$

99 Para una adecuada profundización en la evolución de la concepción metodológica del bien jurídico hacia aquella que divisa en éste un dato pre normativo, remito al insuperado cuadro histórico de ANGIONI, F.: Contenuto e funzioni del concetto di bene giuridico. Giuffré, Milano, 1983. pp. 20 ss. y 70 ss.

100 Se recalca aquí un modelo de intervención ya probado en el pasado por la propia Corte Constitucional en relación con el principio de culpabilidad, cuando, tras la sentencia epónima de 1988 en materia de ignorantia legis, comenzó a llegar a la Corte un altísimo número de solicitudes de reenvío de tribunales que invocaban la abrogación de normas consideradas incompatibles con aquel principio. En muchos casos, la respuesta fue una incitación a los tribunales a colmar de culpabilidad, cuando fuese factible el auxilio de la interpretación, las disposiciones enjuiciadas que parezcan carentes, denunciando a la Corte sólo los casos en que no fuese posible interpretación "adecuadora" alguna.

$101 \quad$ Hoy esto es evidente y explícito, pero en un trabajo de algunos años atrás CATENACCI, M.: "Offensività del reato". En: Dizionario di Diritto pubblico (dirigido por S. Cassese), vol. IV. Giuffré, Milano, 2006. p. 3905, sostenía que esta indicación, que condiciona la labor del juez y del legislador, podía ya encontrarse en sentencias emitidas a finales de los años noventa y principios del nuevo siglo.

102 No se trata de una constatación nueva. La relevó ya CATENACCI, M.: Bene giuridico (Dir. pen.), in Dizionario di Diritto pubblico (dirigido por S. Cassese), vol. IV. Giuffré, Milano, 2006. p. 677. 
En verdad, una reforma legislativa bastante reciente parecería ir en la dirección deseada, pero, acaso, en contra de su intención y, en todo caso, con modalidades discutibles.

Me refiero a la introducción al Código del artículo 131 bis, que regula los casos de exclusión de la punibilidad por el carácter particularmente tenue del hecho. Se trata de la facultad judicial de no aplicar la pena privativa de la libertad o pecuniaria, en delitos de gravedad baja o mediana - penados al máximo con reclusión de cinco años- cuando, por las modalidades de la conducta o la exigüidad del daño o peligro, la ofensa sea particularmente tenue y el comportamiento, no habitual.

Este no es lugar para analizar detallada y críticamente la disposición. Me limito a señalar que con ella el legislador reconoce la existencia de una conducta típica - además de antijurídica y culpable-, cuyo nivel de ofensividad no es nulo, pero de tal modestia que justifica no penarla, salvas algunas excepciones, dada su falta de idoneidad de poner en peligro el bien tutelado.

Se toma nota, pues, de que la ofensa es un elemento del hecho y, asumiendo que su escasa relevancia puede liberar de pena al autor, se entra en la misma lógica que, con mayor razón, yace en el fundamento de la teoría de los hechos inofensivos adecuados al tipo, la que trata, en cambio, de casos de ofensa inexistente.

Ahora, es muy probable que la razón determinante de esta disposición tenga que ver, más bien, con el deseo de producir una deflación en los procesos penales; ${ }^{103}$ pero resta confirmada en nuestro ordenamiento la escisión entre tipicidad y ofensa penalmente relevante.

No obstante, hay que recordar que si esta reforma legislativa puede ser recibida favorablemente en la perspectiva de la afirmación del principio de ofensividad, una serie de otras reformas va en muy otra dirección, con vertiginosas anticipaciones de la tutela, tipos de Derecho penal de autor, de modos de ser y delitos de peligro meramente presunto. ${ }^{104}$

103 Como lo señala, por ejemplo, MANNA, A.: Corso di Diritto penale. Parte generale, $3^{\text {a }}$ ed. CEDAM, Padova, 2015. p. 589, quien, por otra parte, habla con razón de efectos "endo-procesales", dado que un posible efecto de deflación de la población carcelaria está destinado a ser muy escaso o nulo, ya que en los niveles de pena en que actúa la causa de no punibilidad intervienen otras vías de escape a las penas de detención.

104 Por tanto, no ha perdido actualidad la afirmación que formuló hace veinte años PALAZZO, F.: "Offensività e ragionevolezza nel controllo di costituzionalità del contenuto delle leggi penali”. En: Rivista italiana di Diritto e procedura penale, 1998. p. 354, cuando hablaba de "una distancia sideral entre formulación teórico-doctrinal y experiencia legislativa del principio de ofensividad". 
Amenudo se trata de normas "de corto aliento", con las que se pretende responder a la llamada "perenne emergencia", ${ }^{105}$ inútiles y simbólicas, que hacen retroceder peligrosamente el reloj de nuestra cultura jurídica, y frente a las cuales no es admisible una actitud de simple resignación, sino que debe alzarse una crítica, acaso también constructiva, en el intento de identificar los verdaderos intereses merecedores de tutela penal y las modalidades, metodológicas y de contenido, más correctas para el efecto. ${ }^{106}$

Esta crítica debe servirse de los sólidos argumentos identificados por la doctrina y la copiosa jurisprudencia ordinaria y constitucional, para el efecto de imponer el respeto de las exigencias de la ofensividad como principio de estricta inserción en nuestros principios constitucionales.

De hecho, una visión diferente, menos rigurosa, repercutiría negativamente en el ajuste del propio principio de legalidad, dado que, en más de una oportunidad, la Corte Constitucional ha hecho ver que considera que el "hecho" mencionado en el artículo 25 de la Constitución, no es sólo un hecho material, sino también un hecho ofensivo; repercutiría, con mayor evidencia, en el principio de culpabilidad, que postula la necesidad de una conciencia de la ilicitud del hecho que no se puede desligar del carácter ofensivo de éste, $y$, en fin, en la finalidad reeducativa de la pena, que no puede prescindir del reproche por haber

\footnotetext{
105 Cfr. El hermoso libro de MOCCIA, S.: La perenne emergenza. Tendenze autoritarie nel sistema penale. Edizioni Scientifiche Italiane, Napoli, 1995.

106 Lo he intentado recientemente, sugiriendo seleccionar la producción de leyes penales a través de sus modalidades de aprobación y recomendando un quorum parlamentario mucho más elevado que el requerido hoy en Italia (sesenta por ciento de los votantes con derecho, como regla general, y cincuenta por ciento en el caso de la previsión de una pena pecuniaria, frente a la actual mayoría simple de los votantes presentes), de modo que las decisiones de incriminación no sean botín de mayorías arriesgadas y casuales (o, derechamente, de minorías convertidas en mayoría gracias a premios electorales del sistema de mayorías), sino fruto de un verdadero debate y una comunión en valores imprescindibles del ordenamiento. Cfr. FORNASARI, G.: "Argomenti per una riserva di legge rafforzata in ambito penale", de próxima publicación formal en Diritto penale contemporáneo, pero que se puede consultar, adelantado, en https://www.penalecontemporaneo.it/d/6076-argomenti-per-una-riserva-dilegge-rafforzata-in-materia-penale. No diferente en su espíritu es la propuesta anticipada en Alemania por VORMBAUM, T.: Strafrgesetze als Verfassungsgesetze. In memoriam Knut Amelung, in Juristen Zeitung, 2018. p. 53 ss., al paso que en Italia había abocetado hace algunos años una solución análoga MUSCO, E.: L'illusione penalistica. Giuffré, Milano, 2004. p. 183 ss.
} 
lesionado o puesto efectivamente en peligro un bien relevante para el equilibrio del ordenamiento. ${ }^{107}$

\section{Conclusiones.}

Cierto es que en la época del populismo penal y de la confianza ilimitada e instrumental de la política en la expansión del Derecho penal, la afirmación de estas ideas puede parecer una batalla casi contra la corriente.

Sin embargo, hay que responder a estos obstáculos con la conciencia de que la "conservación" del principio de ofensividad es necesaria, ${ }^{108}$ y no debe representar una restyling - remodelación- de fachada, sino asumir la necesidad de adecuar este viejo principio a nuevas exigencias, que pueden nacer de fenómenos como la integración en el proyecto de la Unión Europea, ${ }^{109}$ la globalización, la inserción en el sistema del Derecho penal internacional, $y$, por otra parte, que la lección fundamental que entraña es elemento de identificación de un Derecho penal del Estado democrático de Derecho, teniendo muy en claro que las frecuentes tentaciones de debilitarlo y relativizarlo no son sino un síntoma del deslizamiento hacia un Derecho penal pre-moderno, al que sólo con una incapacidad de ironía grotesca cabe definir, como se pretende hoy, "postmoderno".

107 También en esta frecuencia, DONINI, M.: Il principio di offensività, ob. cit., p. 17, subraya con fuerza que es el estatuto constitucional conjunto del Derecho penal, trazado en Italia por los artículos 25, inc. 2, 27, incisos 1 y 3, 2, 3 y 13 de la Constitución, el que marca el "recinto hermenéutico" dentro del que hay que construir el principio de ofensividad.

Desde una perspectiva distinta, pero complementaria, es interesante que, según una reciente contribución de la doctrina alemana, el hecho de que el legislador no defina netamente la ofensa a un bien jurídico como fundamento de su elección político criminal, torna impracticable toda discusión sobre la dañosidad social del comportamiento y, por tanto, sobre la legitimidad de la intervención penal, porque viene a faltar la base del debate. Cfr. VOGEL, B.: "Zur Bedeutung des Rechtsguts für das Gebot strafgesetzlicher Bestimmtheit”. En: Zeitschrift für die gesamte Strafrechtswissenschaft. 2016. p. 172.

108 En estos términos se expresa PULITANÒ, D.: Offensività del reato (Principio di), en Enciclopedia del Diritto, Annali, ob. cit., p. 684.

109 Al respecto, por ejemplo, son interesantes y cabe compartir las observaciones recientes de MOLINAROLLI, A.: "Una possibile dimensione europea del principio di offensività. Un'analisi integrata dei principi”. En: Diritto penale contemporaneo, 2/2016. p. 21. 


\section{Bibliografía}

ALESSANDRI, A. y GARAVAGLIA, E.: Non passa lo straniero, e www. lavoce.info, 16 de junio de 2008.

ANGIONI, F.: Contenuto e funzioni del concetto di bene giuridico. Giuffré, Milano, 1983.

ANTOLISEI, F.: "Per un indirizzo realistico nella scienza del Diritto penale". En: Rivista italiana di Diritto penale, 1937.

ANTOLISEI, F.: Manuale di Diritto penale, Parte generale. Giuffré, Milano, 2000.

BETTIOL, G.: “Orientamenti generali del Diritto penale”. En: Jus, 1951

BETTIOL, G.: Il problema penale. $2^{\text {a }}$ ed. Priulla, Palermo, 1948, luego incluido en Scritti giuridici, tomo II. CEDAM, Padova, 1966.

BORSARI, R.: "Evasione". En: Fornasari, G. y Riondato, S.: Delitti contro l'amministrazione della giustizia, $2^{\mathrm{a}}$ ed. Torino, 2017

BRICOLA, F.: La discrezionalità nel Diritto penale, vol. I, Nozione aspetti costituzionali. Giuffré, Milano, 1965.

BRICOLA, F.: Teoria generale del reato, en Novissimo Digesto italiano, vol. XIV. UTET, Torino, 1973

BRICOLA, F.: "Legalità e crisi: 1'art. 25, commi 2 e 3 della Costituzione rivisitato alla fine degli anni '70". En: Questione Criminale. 1980.

BRICOLA, F.: "Tecniche di tutela penale e tecniche alternative di tutela". En: Funzioni e limiti del Diritto penale. Alternative di tutela, al cuidado de De Acutis y Palombarini. CEDAM; Padova, 1984

BRICOLA, F.: "Tecniche di tutela penale e tecniche alternative di tutela": En De Acutis, M. y Palombarini, G.: Funzioni e limiti del Diritto penale. Alternative di tutela. CEDAM, Padova, 1984.

BRICOLA, F., SGUBBI, F. Y MAZZACUVA, N.: Dispensa per il Corso di Istituzioni di Diritto penale. Bologna, 1994.

BRICOLA, F.: Scritti di Diritto penale, vol. I. Dottrine generali, teoria del reato e sistemi sanzionatori, tomo I. Dal 1960 al 1973. Milano, 1997.

BRICOLA, F., Scritti di diritto penale, vol. I, tomo II. Milano, 1997. 
BRICOLA: F.: Teoría general del delito, Montevideo-Buenos Aires, 2012. BRUNELLI, D.: "Il disastro populistico". En: Criminalia, 2014.

CADOPPI, A.: "Il principio di irretroattività". En: Insolera, G., Mazzacuva, N., Pavarini. M. y Zanotti, M.: Introduzione al sistema penale, vol. I. Torino, 1997.

CADOPPI, A. y VENEZIANI, P.: Elementi di Diritto penale, Parte generale. CEDAM, Padova, 2015.

CANCIO MELIÁ, M.: “¿«Derecho penal» del enemigo?”. En: Jakobs, G. y Cancio Meliá, M.: Derecho penal del enemigo. Hammurabi, Buenos Aires, 2005.

CANESTRARI, S., CORNACCHIA, L. Y DE SIMONE, G.: Manuale di Diritto penale, Parte generale. Bologna, 2007.

CARRARA, F.: Programma del Corso di Diritto criminale. Parte generale, $3^{\text {a }}$ ed. Tip. Canovetti, Lucca, 1867.

CARRARA, F.: Programma del Corso di Diritto criminale. Parte generale, $10^{\mathrm{a}}$ ed. Fratelli Cammelli, Firenze, 1907.

CATENACCI, M.: "Offensività del reato". En: Dizionario di Diritto pubblico (dirigido por S. Cassese), vol. IV. Giuffré, Milano, 2006.

CATENACCI, M.: Bene giuridico (Dir. pen.), in Dizionario di Diritto pubblico (dirigido por S. Cassese), vol. IV. Giuffré, Milano, 2006.

CATERINI, M.: Reato impossibile e offensività. Un'indagine. Edizioni Scientifiche Italiane, Napoli, 2004.

CAVALIERE, A.: 'Può la 'sicurezza' costituire un bene giuridico o una funzione del diritto penale?”: En Critica del Diritto, 2009.

D'ALESSANDRO, F.: Pericolo astratto e limiti-soglia. Le promesse non mantenute del diritto penale. Giuffré, Milano, 2012.

DELLA BELLA: "Three strikes and you're out: la guerra al recidivo in California e i suoi echi in Italia". En: Rivista italiana di diritto e procedura penale, 2007.

DELL'ANDRO, R.: Il dibattito delle scuole penalistiche. En Archivio penale, 1958. 
DELMAS-MARTY, M.: Aux quatre vents du monde. Petit guide de la navigation sur l'océan de la mondialisation. SEUIL, Paris, 2016.

DELOGU, T.: L'elemento politico nel Codice penale. En Archivio penale, 1945.

DE MAGLIE, C.: "Il declino dell" "harm principle". En: Politica criminale e cultura giuspenalistica, Scritti in onore di Sergio Moccia.

DODARO, G.: "Discriminazione dello straniero irregolare nell'aggravante comune della clandestinità". En: Rivista italiana di Diritto e procedura penale, 2008.

DONINI, M.: "Danno" e "offesa" nella c.d. tutela dei sentimenti. Note su morale e sicurezza come beni giuridici, a margine della categoria dell"offense" di Joel Feinberg". En: Rivista italiana di Diritto e procedura penale, 2008.

DONINI, M.: "Il principio di offensività. Dalla penalistica italiana ai programmi europei". En: Diritto penale contemporaneo, 4/2013.

DONINI, M.: "Il caso Contrada e la Corte Edu. La responsabilità dello Stato per carenza di tassatività/tipicità di una legge penale retroattiva". En: Rivista italiana di Diritto e procedura penale, 2016.

FALCINELLI, D.: "Dal Diritto penale "emozionale" al diritto penale "etico". Il garantismo costituzionale contro l'illusione di giustizia del populismo penale". En: Anastasia, S., Anselmi, M. y Falcinelli, D.: Populismo penale: una prospettiva italiana. CEDAM, Milano-Padova, 2015.

FEINBERG, J.: The Moral Limits of Criminal Law. Oxford University Press, 1984-1988

FEINBERG, J.: Offense to Others, Oxford. University Press, 1985.

FERRAJOLI, L.: "Il paradigma garantista. Per una risposta razionale ai problemi della sicurezza e del terrorismo". En: AA.VV, Politica criminale e cultura giuspenalistica. Scritti in onore di Sergio Moccia,

FERRI, E.: Sociologia criminale. Fratelli Boca, Torino, 1892.

FIANDACA, G.: "Populismo giuridico e populismo giudiziario". En: Criminalia, 2013. 
FIANDACA, G.: Sul bene giuridico. Un consuntivo critico. Giappichelli, Torino, 2014.

FIANDACA, G.: Prima lezione di Diritto penale. Editori Laterza, BariRoma, 2017.

FIORE, C. y FIORE, S.: Diritto penale. Parte generale, $5^{\mathrm{a}}$ ed. UTET Giuridica, Torino, 2016.

FIORELLA, A.: "Responsabilità penale". En: Encicolpedia del Diritto, vol. XXXIX. Giuffré, Milano, 1988.

FORNASARI, G.: "Buona fede e delitti: limiti normativi all'art. 5 c.p. e criteri di concretizzazione". En: Rivista italiana di diritto e procedura penale, 1987.

FORNASARI, G.: "Conquiste e sfide della comparazione penalistica". En: Dolcini, E. y Paliero, C.E.: Studi in onore di Giorgio Marinucci, vol. I, Teoria del Diritto penale, Criminologia e Politica criminale. Giuffré. Milano, 2006.

FORNASARI, G. y PESCE, F.: "Il legislatore alla scuola della razionalità (tra luci e ombre). Il modello di analisi economica del Diritto penale applicato ad alcune esperienze legislative": En: Indice penale, 2016.

FORNASARI, G.: "Un altro passo verso la «riscrittura» della legalità? Appunti sulla sentenza Contrada", En: AA.VV., Politica criminale e cultura giuspenalistica. Scritti in onore di Sergio Moccia. Napoli, 2017.

FORNASARI, G.: "Argomenti per una riserva di legge rafforzata in ambito penale" En: Diritto penale contemporáneo, https://www.penalecontemporaneo. it/d/6076-argomenti-per-una-riserva-di-legge-rafforzata-in-materia-penale

FRANCOLINI, G.: Abbandonare il bene giuridico? Una prospettiva procedurale per la legittimazione del Diritto penale. Giappichelli, Torino, 2014.

GALLO, M.: Appunti di Diritto penale, vol. III, Le forme di manifestazione del reato. Giappichelli, Torino, 2003.

GAMBERINI, A. y ORLANDI, R.: Delitto politico e Diritto penale del nemico. Monduzzi, Bologna, 2007.

GAROFALO, R.: Criminología. Fratelli Boca, Torino, 1891. 
GATTA, G.L.: "Aggravante della "clandestinità" (art. 61 n. 11 bis c.p.): uguaglianza calpestata". En: Rivista italiana di Diritto e procedura penale, 2009.

GOLDSCHMIDT, J.: Normativer Schuldbegriff, en Festgabe für Frank, I, Tübingen, 1930.

GONZÁLEZ CUSSAC, J.L.: "El renacimiento del pensamiento totalitario en el seno del Estado de Derecho: la doctrina del Derecho penal del enemigo". En: Revista penal, 2007.

GROSSI, P.: Scienza giuridica italiana. Un profilo storico 1860-1950. Giuffrè Editore, Milano, 2000.

HARCOURT, B. E.: "The Collapse of the Harm Principle". En: Journal of Criminal Law and Criminology, 1999.

JAKOBS, G.: Strafrecht, Allgemeiner Teil, III Aufl. Berlin, 1990.

JAKOBS, G.: "Das selbstverständnis der Strafrechtswissenschaft vor der Herausforderung der Zukunft". En: Eser, A., Hassemer, W. y Burkhardt, B.: Die deutsche Strafrechtswissenschaft vor der Jahrtausendwende, München, 2000.

LAVACCHINI, M.: La legittimazione dell'intervento penale tra offensività e harm principle. Tesis doctoral, Trento, 2017.

LEONE, G.: La scienza giuridico-penale nell'ultimo ventennio. En Archivio penale, 1945.

LOMBROSO, C.: L'uomo delinquente in rapporto all'antropologia, alla giurisprudenza e alle discipline carcerarie. Hoepli, Milano, 1876.

MANES, V.: Il principio di offensività nel diritto penale. Canone di politica criminale, criterio ermeneutico, parametro di ragionevolezza. Giappichelli, Torino, 2005.

MANES, V.: "I recenti tracciati della giurisprudenza costituzionale in materia di offensività e ragionevolezza". En: Diritto penale contemporaneo, $2 / 2012$.

MANNA, A.: Corso di Diritto penale. Parte generale, $3^{\text {a }}$ ed. CEDAM, Padova, 2015.

MANTOVANI, F.: Diritto penale. Parte generale, $10^{\mathrm{a}}$ ed. Cedam, MilanoPadova, 2017. 
MANZINI, V.: Trattato di Diritto penale italiano, $2^{\mathrm{a}}$ ed. Fratelli Boca, Torino, 1920.

MARINUCCI, G.: "Fatto e scriminanti. Note dommatiche e politicocriminali”. En: Rivista italiana di Diritto e procedura penale, 1983.

MASSARI, E.: Le dottrine generali del Diritto penale. Spoleto, 1928.

MOCCIA, S.: "Dalla tutela di beni alla tutela di funzioni: tra illusioni postmoderne e riflussi illiberali". En: Rivista italiana di Diritto e procedura penale, 1995.

MOCCIA, S.: La perenne emergenza. Tendenze autoritarie nel sistema penale. Edizioni Scientifiche Italiane, Napoli, 1995.

MOLINAROLLI, A.: "Una possibile dimensione europea del principio di offensività. Un'analisi integrata dei principi". En: Diritto penale contemporaneo, 2/2016. p. 21.

MUSCO, E.: L'illusione penalistica. Giuffré, Milano, 2004. p. 183 ss.

NAPPI, A.: Guida al Codice penale, Parte generale. Giuffré, Milano, 2003.

NEPPI MODONA, G.: "Reato impossibile". En: Digesto delle discipline penalistiche, t. XI. Torino, 1996.

NEPPI MODONA, G.: "Il lungo cammino del principio di offensività". En: Studi in onore di Marcello Gallo. Scritti degli allievi. Giappichelli, Torino, 2004.

NOBILI, M.: Il principio del libero convincimento del giudice. Giuffré, Milano, 1974.

NUVOLONE, P.: "Norme penali e principi costituzionali". En: Giurisprudenza italiana, 1956.

NUVOLONE, P.: Natura e storia della scienza del Diritto penale. 1951, en ídem, Trent' anni di Diritto e procedura penale, vol. I. CEDAM, Padova, 1969.

ONIDA, V.: "Efficacia non scontata per il ricorso al penale". En: Il Sole 24 ore, 22 de mayo de 2008.

ORLANDO, V. E.: I criteri tecnici per la ricostruzione giuridica del Diritto pubblico. En Archivio Giuridico, vol. XVII, 1889.

PAGLIARO, A.: Principi di Diritto penale, Parte generale. Giuffré, Milano, 2003. 
PALAZZO, F.: Il principio di determinatezza nel Diritto penale. CEDAM, Padova, 1979.

PALAZZO, F.: "Offensività e ragionevolezza nel controllo di costituzionalità del contenuto delle leggi penali”. En: Rivista italiana di Diritto e procedura penale, 1998.

PALIERO, C. E.: "Sicurezza dei mercati o mercato delle (in)sicurezze?". En Donini, M. y Pavarini, M.: Sicurezza e Diritto penale. Bononia, University Press, Bologna, 2011.

PASCULLI, Così L: “«Harm», «Offence» and «Offesa» in the english and italian criminal law. For a constitutionalisation of a unitary principle of harm in the english legal system, also as criterion of judicial interpretation". En: Diritto penale XXI secolo, 2016.

PRITTWITZ, C.: "Società del rischio e Diritto penale". En Foffani, L. y Stortoni, L.: Critica e giustificazione del Diritto penale nel cambio di secolo. L'analisi critica della Scuola di Francoforte. Giuffré, Milano, 2004. PULITANÒ, D.: L'errore di Diritto nella teoria del reato. Giuffré, Milano, 1976. PULITANÒ, D.: “Obblighi costituzionali di tutela penale?”. En Rivista italiana di Diritto e procedura penale, 1983.

PULITANÒ, D.: Populismi e penale. Sulla attuale situazione spirituale della giustizia penale, ivi.

PULITANÒ, D.: “Tensioni vecchie e nuove sul sistema penale". En: Diritto penale e processo, 2008.

RIZ, R.: Lineamenti di Diritto penale, Parte generale. CEDAM, Padova, 2006.

ROCCO, A.: "Il problema e il metodo della scienza del Diritto penale". En: Rivista di Diritto e procedura penale.

ROCCO, A.: Opere giuridiche, vol. III. Edizioni del Foro, Roma, 1933.

SILVANI, S.: "Definitivamente estromessa dal sistema penale l'ubriachezza manifesta". En: Giurisprudenza Costituzionale, 2002.

STELLA, F.: "La teoria del bene giuridico e i c.d. fatti inoffensivi conformi al tipo". En: Rivista italiana di Diritto e procedura penale, 1973.

TRAPANI, M.: "Guerra e diritto penale. Sull'adeguatezza degli strumenti penalistici nei confronti del c.d. terrorismo islámico". En AA.VV., Politica criminale e cultura giuspenalistica. Scritti in onore di Sergio Moccia. 
VOGEL, B.: "Zur Bedeutung des Rechtsguts für das Gebot strafgesetzlicher Bestimmtheit". En: Zeitschrift für die gesamte Strafrechtswissenschaft. 2016.

VORMBAUM, T.: Strafrgesetze als Verfassungsgesetze. In memoriam Knut Amelung, in Juristen Zeitung, 2018.

ZAFFARONI, E.R.: El enemigo en el Derecho penal. Ediar, Buenos Aires, 2006.

ZIZEK, S.: La tentazione populista, en H. Geiselberger, La grande regressione. Quindici intellettuali da tutto il mondo spiegano la crisi del nostro tempo. Feltrinelli, Milano, 2018.

ZUCCALÀ, G.: Il delitto preterintenzionale. Priulla, Palermo, 1952. 